\title{
Tensions at the intersection of management control and innovation: a literature review
}

\author{
Eva Lövstål ${ }^{1}$ (D) Anne-Marie Jontoft ${ }^{1}$
}

Published online: 4 February 2017

(C) The Author(s) 2017. This article is published with open access at Springerlink.com

\begin{abstract}
This paper reviews 47 articles dealing with tensions at the intersection of management control and innovation. One purpose is to present the status of the research in the area in terms of types of articles, research methods, theoretical approaches, and tension-related terms used. A second purpose is to conceptually compare the use and interpretations of tension in the reviewed articles, as well as to systematically map and categorize highlighted competing demands. A third purpose is to suggest a tension-based framework. Among other characteristics and trends, the paper indicates an increased research interest in the issue of tensions during the review period (1991-2015). Although different theoretical approaches are adopted, the contingency approach is the most common. Furthermore, the review shows that several tension-related terms are used either alone or in parallel in the articles, often interchangeably and without clarifying their definitions. The tension-based framework presents four different types of tension: (1) inherent innovation-control tensions, (2) inherent management control tensions, (3) created management control tensions, and (4) decision-making tensions in innovation practices. The framework also suggests interpretations of and responses to tensions related to management control and innovation. Theoretically, the framework can enable a more precise debate that builds on previous research, since it clarifies potential ways to structure future research. From a practical point of view the presented framework can be helpful for managers dealing with tensions, by encouraging creative management control solutions that can enable innovation.
\end{abstract}

\footnotetext{
Eva Lövstål

eva.lovstal@hkr.se

Anne-Marie Jontoft anne-marie.jontoft@hkr.se

1 Department of Business Administration and Work Science, Kristianstad University, 29188 Kristianstad, Sweden
} 
Keywords Management control $\cdot$ Innovation $\cdot$ Tension $\cdot$ Literature review

JEL Classification M190

\section{Introduction}

Managing innovation has become a central topic in strategy, organization and innovation literature (cf. Eisenhardt et al. 2010). In fast-paced, complex and competitive times, it is suggested that the success of an organization can be explained by its management of innovation (Adams et al. 2006; Brühl et al. 2010). In line with this, it is also stressed that the management of innovation- "in its many forms" (Khazanchi et al. 2007, p. 871) —is an important responsibility of today's managers (ibid.). In an emerging stream of research, management control—which deals with the question of how to influence employees' behaviours towards organizational goals (cf. e.g. Alvesson and Kärreman 2004; Malmi and Brown 2008) —is acknowledged as an important aspect of innovation management (e.g. Davila et al. 2009; Janssen et al. 2011; Bedford 2015). It is argued that an organization's management control system may have an impact on its innovation activities and processes (e.g. Davila et al. 2009; Adler and Chen 2011). Mundy (2010), for example, stresses that not using management control systems, or using them inappropriately, may hamper innovation.

Some literature discussing management control in relation to innovation emphasizes that these two phenomena create competing organizational demands. As an example, managers need to strive for predictable goal achievement while at the same time they have to look beyond predictability to aspire to innovation (see e.g. Simons 1995). Similar competing demands are expressed by Perez-Freije and Enkel (2007), who state that "While some degree of freedom and flexibility is essential for productive innovation teams, management is faced with the challenge of instituting control mechanisms that lead projects in the right strategic direction..." (p. 11). These kinds of competing demands raise tensions in an organization (cf. e.g. Smith and Lewis 2011; Gaim and Wåhlin 2016). Accordingly, and given that management control and innovation involve competing demands, like the ones mentioned above, it requires a capability to manage tensions (e.g. Breunig et al. 2014; Pärl 2014). However, the literature does not offer a clear understanding of tensions at the intersection of management control and innovation. The ongoing debate seems to be rather vague and fragmented. For example, researchers use various terms and definitions when describing and studying tensions - terms and definitions that reflect different views of the tensional relationship between management control and innovation (cf. Gaim and Wåhlin 2016). Also, it is not definite what the competing demands are and what it means to manage tensions at the intersection of management control and innovation. Further, and considering that innovation management covers both strategic and operative aspects and at different organizational levels (cf. Magnusson et al. 2009), it is unclear where and why competing demands occur.

Previous reviews show that contingency theory is the most frequently used theoretical framework in studies dealing with management control and innovation (Davila et al. 2009). A number of researchers have emphasized the need for other theoreti- 
cal approaches when studying management control and innovation (e.g. Davila et al. 2009) as well as tensions (e.g. Smith and Lewis 2011). It has also been suggested that there is a need for more empirical studies (e.g. Gaim and Wåhlin 2016), particularly qualitative studies and studies that investigate tensions in depth and close to practice (e.g. Lewis and Smith 2014). It is not clear whether these ideas have had an impact on studies dealing with tensions at the intersection of management control and innovation. Hence, there is a need to investigate and describe recent developments and the present status in this research area.

This paper presents a literature review of articles and studies dealing with tensions at the intersection of management control and innovation. One purpose of the paper is to present - in a synthesized way - the status of the research in the area in terms of types of articles, research methods, theoretical approaches, and tension-related terms used. A second purpose is to conceptually compare the use and interpretations of tension in reviewed articles, as well as to systematically map and categorize highlighted competing demands. In this work, we draw on more general research and conceptualizations on tensions, management control and innovation. A third purpose is to suggest a tension-based framework that is grounded in both previous research on tensions in general and on the specific results of our literature review. An organized framework that builds on previous research may offer new understandings and potential ways to structure future research (Davila et al. 2009).

This paper contributes to the literature on management control and innovation by focusing on tensions. It is claimed that such a focus may contribute to the research on management control and innovation by increasing our understanding of their relationship (e.g. Davila et al. 2009). This may in turn increase our knowledge about how to deal with these two phenomena and associated tensions. Furthermore, by presenting the state of the art regarding research on tensions at the intersection of management control and innovation, the paper shows some directions for future research. As another contribution, we add to the literature by clarifying the meaning of tension and by identifying and categorizing competing demands. This addresses the vague and fragmented way in which tensions have been studied and understood to date. As, for example, Raza-Ullah et al. (2014) argue, only after tensions have been identified and conceptualized can they be approached and dealt with. In response to the need for an organized framework, a last contribution is our tension-based framework, which brings some essential tension-related pieces together.

The remainder of the paper is outlined as follows. The next chapter presents the theoretical background, more precisely, theoretical concepts and reasoning that were used when reviewing the literature and when analysing and interpreting its contents on tensions and competing demands. Thereafter, we describe the methodology for identifying and scrutinizing the literature. After describing our literature review process, we present the descriptive results which reflect the status of the research on tensions, regarding, for example, theoretical approaches. This is followed by a more elaborative chapter in which we identify and discuss different types of tensions and categories of competing demands. This chapter ends with our tension-based conceptual framework. Finally, we reflect upon the results and their possible theoretical and practical implications. We also discuss insights for future research. 


\section{Theoretical background}

\subsection{Management control and innovation}

The discussion regarding the relevance of management control in the context of innovation has changed significantly in recent decades. Previously, formal management control was seen as irrelevant or even detrimental in processes of innovation and development (Bisbe and Otley 2004). For example, Roberts (1991) argues that formal controls, such as budgetary control, stifle innovation and learning because they encourage behaviours driven by egoism, hierarchical dependence and risk aversion. However, in more recent research this traditional view has been questioned, and management control is seen not only as something that can coexist with innovation, but also as a facilitator for innovation (e.g. Davila 2000; Ahrens and Chapman 2004; Bisbe and Otley 2004; Davila et al. 2009; Haustein et al. 2014).

The field of innovation is characterized by a variety of approaches to and definitions of "innovation" (Adams et al. 2006; Baregheh et al. 2009; Crossan and Apaydin 2010). As Crossan and Apaydin's (2010) literature review reveals, innovation has been approached as both a process and an outcome. As an outcome, it can take many forms and be of different magnitudes. For example, an innovation can be a product, process, position or business model (see e.g. Francis and Bessant 2005). Seen as a process, innovation addresses several organizational levels, such as individual, group and firm level, as well as different loci, in terms of closed or open processes (Crossan and Apaydin 2010). Considering the purposes and focus of our paper, we approach innovation broadly and adhere to a definition similar to the one suggested by Baregheh et al. (2009). They define innovation as a "multi-stage process whereby organizations transform ideas into new/improved products, service or processes, in order to advance, compete and differentiate themselves successfully in their marketplace" (p. 1334). This definition acknowledges both the outcome- " "new/improved products, service and processes" - and the innovation process. It also stresses the aim of innovation, as, for example, to successfully compete on the market. However, they describe the innovation process as "a multi-stage process". Similar to some other researchers, we suggest that innovation is more complicated than that, involving many parallel and iterative processes at different organizational levels. This is stressed, for example, by Davila et al. (2009). They note: "Innovation is not a monolithic phenomenon but various processes that coexist in parallel, each one requiring different types of control systems" (p. 284). Thereby, they also stress that this has implications for management control. In the context of innovation, management control is multifaceted, covering control systems at the strategic innovation process level as well as, for example, for new product development projects.

However, in innovation literature, the concept of management control is not always explicitly used. Sometimes the phenomenon is dealt with by using other words, such as "innovation control" (e.g. Janssen et al. 2011). At other times it is dealt with more indirectly. For example, in their framework, Crossan and Apaydin (2010) include organizational structure and management systems as firm-level elements that may enable innovation, and project management as an element on a business process level. 
These elements can be argued to address issues that are closely related to management control, even if it is not mentioned explicitly.

The literature on management control contains several definitions and conceptualizations on management control and management control systems (MCS) (Strauss and Zecher 2013). More recent models are broader than earlier ones, something which is argued to be relevant in the context of innovation and thus also in line with this paper's approach to management control and MCS. Merchant and Stede (2012), for example, present a broad definition that embraces many different forms of control, including more informal and social ones. They define MCS as "all the devices or systems managers use to ensure that the behaviours and decisions of their employees are consistent with the organization's objectives and strategies" (p. 6; see also e.g. Alvesson and Kärreman 2004). Davila (2000) emphasizes that management control cannot be limited to traditional accounting measures when dealing with innovation and new product development. Instead, a broader set of measures is needed (cf. also Adams et al. 2006, on output and input measures). Haustein et al. (2014), for their part, highlight that within the context of innovation, research strives to investigate a holistic view of the entire management control system rather than single control instruments. Such a holistic view is reflected, for example, in Malmi and Brown's (2008) package of controls and Simons' (1995) well-used levers of control model.

Tessier and Otley (2012) present a revised version of Simons' (1995) levers of control model. Their framework focuses in detail on the dual role of management controls in order to promote both innovation and predictability. In their model, managerial controls are categorized into three different dimensions: (1) types of controls (2) purposes of controls, and (3) use of controls. The first dimension takes into account the controls that are available to managers and refers to the type of control—in other words, this dimension addresses the question of what. The second dimension describes the purposes of controls and answers the question of why management controls are used (cf. MCS roles in Davila et al. 2009). Lastly, the third dimension Tessier and Otley (2012) discuss in their model is use of controls. This dimension relates to managerial intentions and therefore answers the question of how management controls are used by managers, for example, how intensely they are used (see e.g. Tessier and Otley's discussion on p. 177).

Accordingly, the discussion regarding the relevance of management control in the context of innovation has changed in the last decades, and many researchers nowadays acknowledge management control as an important factor to consider in the context of innovation. While the importance of management control is stressed, it is also described as a difficult and challenging task (Chiesa et al. 2009; Janssen et al. 2011). One reason for this is that management control and innovation may raise tensions in an organization, as previously suggested.

\subsection{Interpretations of and responses to tensions}

As mentioned in the introduction, tensions arise when there are competing organizational demands (see e.g. Smith and Lewis 2011). In literature dealing with tensions, these competing demands are often expressed in opposite terms or as opposing ele- 
ments, such as stability and change, exploitation and exploration, and efficiency and flexibility (ibid.; Gaim and Wåhlin 2016).

Being composed of competing demands, a tension can be labelled and interpreted in different ways. Sometimes tensions are discussed in terms of a duality. In a duality, competing demands are both contradictory and complementary and should be managed simultaneously and in their entirety (Achtenhagen and Melin 2003; see also Janssens and Steyaert 1999). Another interpretation is reflected in the notions of dilemma and trade-off. According to Achtenhagen and Melin (2003), dilemmas occur when it is difficult to choose between two options with both advantages and disadvantages. A trade-off, on the other hand, can be seen as a number of solutions on a continuum between two opposite poles. Yet another interpretation is expressed when labelling a tension as a dialectic. A dialectic indicates an ongoing process of resolving tensions through integration (Smith and Lewis 2011). This interpretation incorporates competing demands that can be resolved into a combined synthesis. However, over time new dialectic tensions will emerge that have to be resolved (Barnson 2014). A last possibility is captured in the term paradox. A paradox is similar to a duality, since neither of them allows for a choice between two options or choices on a continuum. A paradoxical tension is characterized by two competing demands that individually seem logical but when put together seem inconsistent, or even absurd (see e.g. Smith and Lewis 2011).

Since the terms represent different interpretations of a tension, they also reflect different responses to tensions. For example, whereas a dilemma seems to involve a weighing of pros and cons, a dialectic points at a merger of opposing elements "into a combined element" (Smith and Lewis 2011, p. 386). A trade-off asks for a balance between two opposite poles. Gaim and Wåhlin (2016) call this response "suppression" since one element is favoured at the expense of the other (p. 35). The question of how to respond to a paradox seems to be a particularly intriguing one, since a paradox cannot be resolved and since it persists over time. Here, one suggestion is to simply learn to live with it, to accept it (see e.g. Poole and Ven 1989, p. 566). Another suggested response to tensions, also presented by Poole and Van de Ven (ibid.), is to separate opposing elements in time or space. This response seems to be a possible alternative when looking at a tension as a duality. It acknowledges that both opposing elements are needed, but they are managed by changing focus from one element to another. A summary of tension-related terms, their interpretations and suggested responses-as described in conceptual papers on tension-is presented in Table 1 below.

However, and as Smith (2014), for example, stresses, these tension-related terms are often used interchangeably and without real consideration of their differences.

\subsection{Different perspectives on tension}

According to Smith and Lewis (2011), researchers have explored tensions in different ways, for example, as either latent or salient. Latent tensions are defined by Smith and Lewis as "contradictory yet interrelated elements embedded in organizing processes that persist because of organizational complexity and adaptation" (p. 389). This means that they are embedded and exist naturally within the organization. Several authors 
Table 1 Different interpretations of and responses to tensions. (Table developed from: Lövstål 2008, p. 60)

\begin{tabular}{|c|c|c|}
\hline Tension-related term & Interpretation & Suggested response \\
\hline A dilemma & An impossible choice & $\begin{array}{l}\text { Weighing pros and cons } \\
\text { Choosing one element }\end{array}$ \\
\hline A trade-off & Possible solutions on a continuum & $\begin{array}{l}\text { Finding a proper balance } \\
\text { Finding the greatest fit }\end{array}$ \\
\hline A duality & $\begin{array}{l}\text { Contradictory and complementary } \\
\text { demands }\end{array}$ & $\begin{array}{l}\text { Separating opposing elements in time } \\
\text { or space }\end{array}$ \\
\hline A dialectic & $\begin{array}{l}\text { Contradictory elements that can be } \\
\text { resolved through integration }\end{array}$ & $\begin{array}{l}\text { Creating a new alternative by } \\
\text { combining elements }\end{array}$ \\
\hline A paradox & $\begin{array}{l}\text { Simultaneous presence of } \\
\text { contradictory demands that persist } \\
\text { over time }\end{array}$ & $\begin{array}{l}\text { Accepting and intensifying } \\
\text { Reframing the problem }\end{array}$ \\
\hline
\end{tabular}

label this type of tension as an "inherent organizational tension" (see e.g. Simons 1995; Henri 2006; Hodgson and Briand 2013). Smith and Lewis (2011) define salient tensions as "contradictory yet interrelated elements experienced by organizational actors" (p. 389). Unlike latent tensions, they are social constructions since they are perceived by the actors and captured in their rhetoric. In other words, latent tensions reflect a practitioner's perspective on tensions.

The notion of tension has also been discussed from different theoretical perspectives. In the literature two overall theoretical perspectives are often discussed and juxtaposed. These are the contingency and the paradox approaches. Lewis and Smith (2014) state that many of the early researchers have responded to organizational tensions by applying a contingency approach. According to them, a contingency perspective addresses tensions as discrete organizational problems that have to be solved. A core premise is that an alignment between managerial decisions and contingencies affects performance in a positive way (ibid.). As a result, studies within this theoretical school seek to identify the pros and cons of opposing elements as well as the requirements in the present context in order to determine the option that offers the best fit. However, there are exceptions. Normann (1975) is one such exception since he asks for "misfits", arguing that "misfits or conflicts [are] highly desirable and necessary" (p. 136; our translation). According to Gaim and Wåhlin (2016), for example, the contingency approach reflects an either-or perspective, since it is based on choice. From a contingency perspective, a tension should be dealt with by favouring one competing demand at the expense of the other.

Smith and Lewis (2011), as well as Alvesson and Kärreman (2004), stress that there has been a strong tendency in previous management literature to emphasize an either-or orientation to tensions and to adopt approaches such as the traditional contingency one. As an alternative, they advocate a paradoxical approach to tensions, which reflects a both-and perspective (see also Lewis and Smith 2014; Gaim and Wåhlin 2016). Such an approach explores tensions across organizational phenomena and at different organizational levels of analysis, similar to the contingency approach 
(Smith and Lewis 2011). According to Barnson (2014), a main difference between the two is that a paradoxical approach wants to explore how people can attend to competing organizational demands simultaneously and over time, and not how they should get rid of them. A paradoxical approach assumes that tensions persist within complex and dynamic systems, and that these tensions are beneficial and essential (Smith and Lewis 2011). Therefore, it is important to be able to manage competing demands simultaneously in order to achieve sustainability (Barnson 2014).

Finally, some researchers have also stressed the importance of studying tensions at different organizational levels. Magnusson et al. (2009), as one example, highlight this need in their introduction to a special issue. They suggest that tensions require different solutions at different levels. Therefore, we need to study tensions at an overall firm level, as well as at departmental and project levels. Aubert et al. (2015) claim that one possible way to theoretically elaborate on tensions is to clarify the level of analysis and related competing demands (see also Smith and Lewis 2011).

\section{Research design}

When conducting our literature review, we considered the guidelines proposed by Tranfield et al. (2003) and Cooper (2009). In order to accomplish a comprehensive and impartial search, we took a multi-step search approach to identify the seminal works dealing with the topic (cf. Lueg and Radlach 2016).

In a first step we determined the keywords and inclusion criteria. Regarding the selection of keywords, we wanted to identify a search string that captured the notion of tension in the context of management control and innovation. Therefore, we started by using three keywords in the search string, in all search fields including title, keywords and abstract:

["management control*"] and [innovation*] and [tension*]

However, due to our broad definitions of management control and innovation, and due to diverse terminology, we successively_-for each keyword-used closely related concepts as well as their abbreviations. The different keywords on tension are based on the conceptual discussion on tension-related terms (summarized in Table 1). However, in addition to these, we also included "balance" as a keyword in the search process. We did this to ensure that our review would include those articles that discussed a balance between competing demands even if they did not explicitly mention specific tensionrelated terms. Moreover, we used the asterisk as a wild card within the searches. Altogether, our search process covered the following keywords, which formed the total search string (Table 2).

The search process resulted in 105 different search modes. ${ }^{1}$ Throughout the search process we considered only peer-reviewed articles published in English-language jour-

\footnotetext{
1 For example, 15 search modes could be related to the keyword tension*, that is: ("management control*" AND innovation* AND tension*) OR ("management control*" AND "new product development*" AND tension*) OR ("management control*" AND NPD AND tension*) OR ("management control*" AND "research and development*" AND tension*) OR ("management control*" AND R\&D AND tension*) OR ("control system*" AND innovation* AND tension*) OR ("control system*" AND "new product
} 
Table 2 Keywords used in the search process

\begin{tabular}{lll}
\hline "Management control*" & Innovation* & Tension* \\
\hline "Control system*" & "New product development*" & Balance* \\
"Innovation control*" & NPD & Paradox* \\
& "Research and development*" & Trade-off* \\
& R\&D & Dilemma* \\
& & Dialectic* \\
\hline
\end{tabular}

nals. Two additional inclusion criteria were that the articles should be within (1) the subject area of management/business and considered as either (2) an original or theoretical paper (therefore review articles were excluded). Regarding publication year, we initially planned to include only articles published in 2000 or later, since the main aim of the review was to investigate recent developments and the present status of the research. We later extended the period to 1990-2015 in order to see the development over a longer time period. However, this extension resulted in only two more articles.

In the second step, we performed database searches in Google Scholar and scientific databases, such as Business Source Complete (EBSCO), Emerald, SAGE, Social Science Citation Index (SSCI), Science Direct and Wiley. Moreover, to accomplish an adequate search, complementary search strategies were needed to find relevant studies (Cooper 2009). Therefore, to ensure that relevant studies were found, our search strategy also included the scrutiny of recommended articles and reference lists. This search eventually resulted in a catalogue of nearly 250 articles, after eliminating duplicates.

Third, we performed a cursory content analysis of the remaining articles, primarily by reading titles and abstracts. By doing this, we eliminated articles that did not cover the topic of our research and/or did not meet our inclusion criteria despite being selected in the search. For example, by including the keyword "balance*" we received a number of articles that dealt with balanced scorecard but did not discuss competing demands or tensions. The keyword "control system*" also resulted in a number of irrelevant hits. Further, not all of the databases could properly handle the inclusion criteria of subject area. Therefore, a number of articles within other scientific areas, such as medicine, computer science and engineering, had to be removed. The search processes and content analyses finally left us with 47 articles.

In the fourth and final step, we analysed the 47 articles in three processes, namely, (1) a general extraction process, (2) a topic-specific extraction process, and (3) a syn-

\section{Footnote 1 continued}

development*" AND tension*) OR ("control system*" AND NPD AND tension*) ("control system*" AND "research and development*" AND tension*) OR ("control system*" AND R\&D AND tension*) OR ("innovation control*" AND innovation* AND tension*) OR ("innovation control*" AND "new product development*" AND tension*) OR ("innovation control*" AND NPD AND tension*) OR ("innovation control*" AND "research and development" " AND tension*) OR ("innovation control*" AND R\&D AND tension*). 
thesizing analysis on tensions (cf. Tranfield et al. 2003). The first process involved the development of a data-extraction form containing general information such as title, author, publication details, article type, empirical setting, and methodology and data collection methods. Thereafter, a second extraction-more related to tensions-was conducted. Here, we documented the occurrence of tension-based terms, mentioned opposing elements, and theoretical approaches used. This extraction process required more careful reading of both abstracts and articles. We started the process by independently analysing articles and thereafter discussing and comparing our results, as suggested by, for example, Tranfield et al. (2003). These discussions also resulted in adjustments and changes in the extraction form. After we had developed a joint view of the extraction process, we divided the articles between us and analysed them separately. The results of the two extraction processes are mainly presented in Sect. 4. Finally, we conducted a synthesizing analysis on tensions with the aim of summarizing and integrating results and characteristics of previous studies and articles (Tranfield et al. 2003; Cooper 2009). In our case, this synthesis was conducted in a qualitative way, looking for differences and similarities related to, for example, highlighted opposing elements, interpretations of tensions and types of tensions. This process required a lot of collaboration, discussion and reading. Here, we also used conceptual models and categorizations presented in Sect. 2, related to both management control (e.g. Tessier and Otley 2012) and tension (e.g. Smith and Lewis 2011), as inspiration and support for our work. The results of our synthesizing analysis are presented in Sect. 5 .

\section{Descriptive results of literature review}

\subsection{Publication and types of articles}

A table summarizing the results from our general extraction process of the articles can be found in "Appendix 1". It presents information about the author, journal, article type, methodology and data collection methods. "Appendix 2" summarizes the represented journals and their frequencies; it reveals that 29 different journals are included in our review. Most of the journals (22) have only one article dealing with the topic; Accounting, Organization and Society stands out, however, with nine relevant articles.

A majority of the journals are within the fields of accounting and management control. However, general management journals, such as European Management Journal, and journals within innovation management are also represented. For example, two articles were published in the Journal of Product Innovation Management.

Figure 1 presents the publication years of the reviewed articles. The dotted line in the diagram implies an increased interest in the issue of tensions at the intersection of management control and innovation. In the 90 s and the very beginning of 00s, only three articles were published. In the middle of the 00s we can see a slight increase. We found no publication in 2008, but a large increase in the following year compensates for that. Since 2009, articles on the topic were published at a fairly constant rate, and at a generally higher level than previous years.

Figure 1 also presents the frequency of types of articles - original or theoretical—in each year. In total, original articles, presenting empirical findings and observations, 


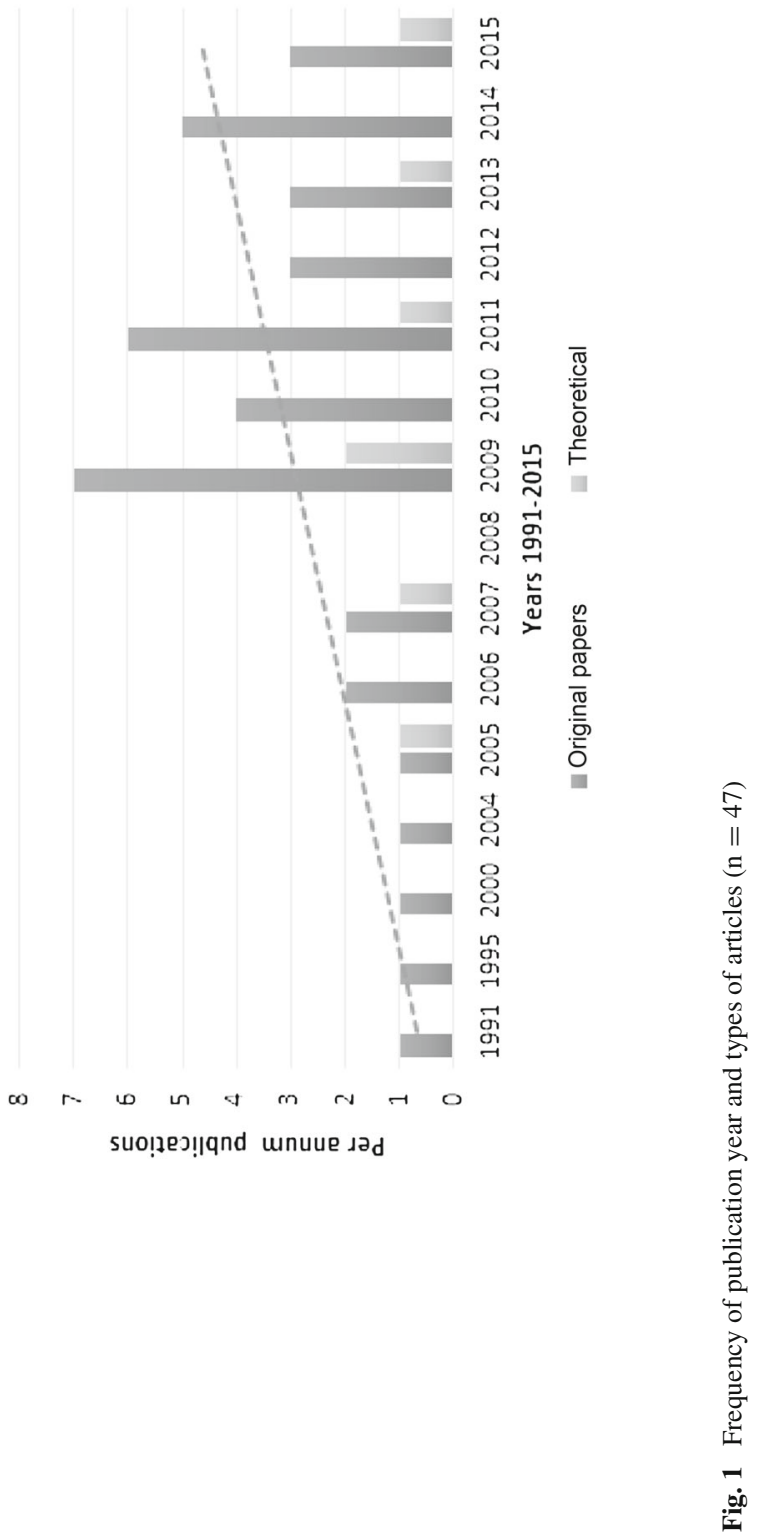


were the most common; $40(85 \%)$ of the articles were classified as original. Seven theoretical articles $(15 \%)$ were found in the review process.

\subsection{Methodology and data collection methods}

Among the 40 original articles, $24(60 \%)$ were interpreted as having mainly a qualitative methodology. In the remaining 16 articles (40\%), a quantitative methodology was used. Figure 2 presents a more detailed description of the research strategies used.

As the diagram reveals, almost two-thirds of the relevant articles used a case-study approach. Among the studies, 13 (32\%) were conducted within a single organization. Almost as many (11) employed a case-study approach in two or more organizations. Fifteen (38\%) of the 40 original articles presented empirical findings from a survey study. One study adopted a case-survey approach. This is the study by Davila et al. (2009), which is based on a cross-sectional, multi-method and multi-case field research design.

Regarding data collection methods, interviews were the most common one in studies using a case-based methodology. However, other data collection methods were also used, including participant observation and archival data. Some of these studies have taken an in-depth exploratory case-study approach that combines observations with archival data and interviews. Within the survey studies,questionnaires were used either as the sole method or combined with interviews. Through our analysis we noted that the empirical material is based almost exclusively on interviews with and questionnaires directed towards managers in the organization; the managers were at various levels and in different departments. The employee perspective is missing in most studies. Only a few studies, which have the team as the level of analysis, incorporated the team members in the empirical investigation. Information about methodological approaches, research strategies and data collection methods on each individual article can be found in "Appendix 1".

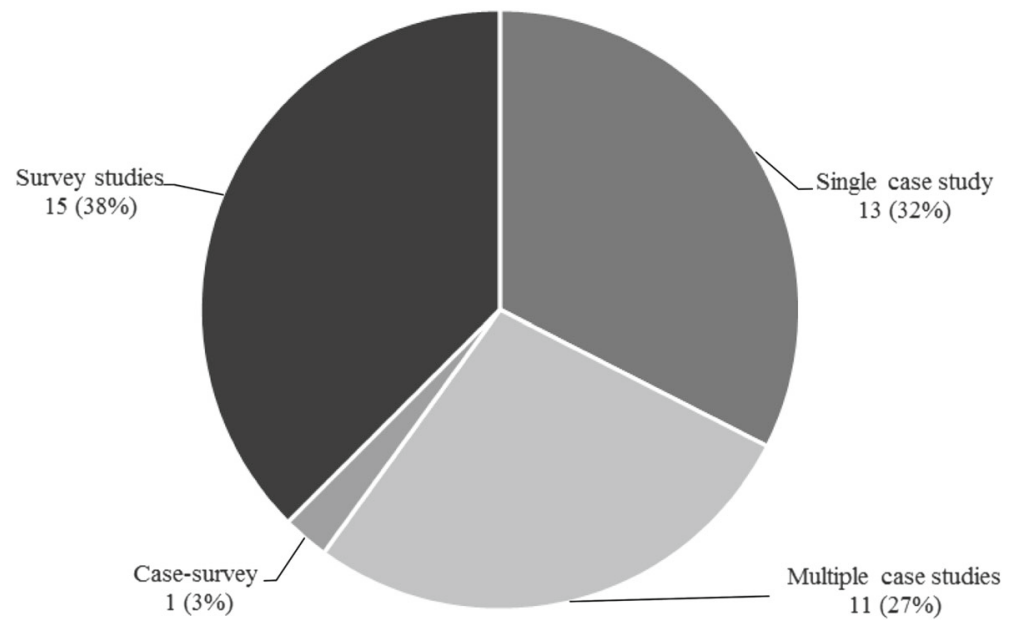

Fig. 2 Distribution regarding research strategies 1991-2015 $(n=40)$ 


\subsection{Tension-related terms}

One of the requirements for including an article in the literature review was that a tension should be explicitly stressed, by using either one or several tension-related terms (presented in Table 1) or by discussing it in terms of a balance between competing demands. In 38 of the 47 articles, the overall term "tension" occurs. However, several other tension-related terms and expressions appear in the articles, either alone or in parallel with others. The number of articles using each term is illustrated in Table 3. More detailed information about the usage of tension-related terms is presented in the last column of "Appendix 1".

The concept of "balance" is the second most common term (referred to in 34 articles; e.g. Kruis et al. 2015). Next after "balance" come "paradox" (in 11 articles; e.g. Pärl 2014; Aubert et al. 2015), "trade-off" (in 10 articles; e.g. Harris et al. 2009; Jørgensen and Messner 2010), “dilemma” (in nine articles; e.g. Kivisaari 1991; PerezFreije and Enkel 2007; Knardal and Pettersen 2015), and "dialectic" (in seven articles; see Theule and Fronda 2005; Jeacle and Carter 2012). The term "duality" occurs in seven articles, in expressions such as "dual challenge" (Adler and Chen 2011), "dual objective" (Brattström and Richtnér 2014) and "dualism" (Revellino and Mouritsen 2015). A less commonly used term, which is not captured in Table 1, is "antithetical" (referred to in three publications; Chenhall and Morris 1995; Goodale et al. 2011; Hodgson and Briand 2013). In 16 articles, the overall terms "tension" and "balance" were the only ones used, either alone or together. In the remaining articles, the more specific terms (i.e. paradox, trade-off, dilemma, dialectic, duality or antithesis) occur. In 13 articles, two or three of these terms were used in parallel. Regarding the use of the different tension-related terms over time, "duality" was not used in the earlier articles. It appeared first in 2009. Besides this, our review does not indicate that the frequencies of the terms changed during the review period.

In many articles the terms are used without any further definition or explanation. When they are explained it is frequently done in terms of "contradictory logics" (Breunig et al. 2014), "competing demands" (Frow et al. 2005), "a conflicting pressure" (Knardal and Pettersen 2015) and "opposing logics" (Pärl 2014). One exception, in which the meaning of the term is elaborated on, is the article by Aubert et al. (2015). They discuss the interpretation of "paradox" by referring to, for example, Eisenhardt

Table 3 Number of articles using tension-related terms

\begin{tabular}{ll}
\hline Tension-related term & $\begin{array}{l}\text { Number of articles using the } \\
\text { specific term }(\mathrm{n}=47)\end{array}$ \\
\hline Tension & 38 \\
Balance & 34 \\
Paradox & 11 \\
Trade-off & 10 \\
Dilemma & 9 \\
Dialectic & 7 \\
Duality & 7 \\
Antithesis & 3 \\
\hline
\end{tabular}


Table 4 Theory approaches used

\begin{tabular}{|c|c|c|}
\hline Theory approach & No. of articles & References \\
\hline Contingency approach & 20 & $\begin{array}{l}\text { E.g. Davila (2000), Perez-Freije and Enkel } \\
\text { (2007), Verbeeten and Boons (2009) and } \\
\text { Canonico and Söderlund (2010) }\end{array}$ \\
\hline Practice-oriented approach & 8 & $\begin{array}{l}\text { E.g. Jørgensen and Messner (2010), Akroyd } \\
\text { and Maguire (2011) and Breunig et al. } \\
\text { (2014) }\end{array}$ \\
\hline Dynamic capabilities approach & 4 & $\begin{array}{l}\text { E.g. Henri (2006), Harris et al. (2009) and } \\
\text { Brühl et al. (2010) }\end{array}$ \\
\hline Paradox (duality) approach & 2 & $\begin{array}{l}\text { E.g. Carter et al. (2013) and Aubert et al. } \\
\text { (2015) }\end{array}$ \\
\hline Other/none & 13 & \\
\hline
\end{tabular}

(2000) and Smith and Lewis (2011). They end up defining a paradox as "the joint existences of two elements that seem logical when considered in isolation, but appear incompatible when considered together" (p. 256). In addition, a couple of articles elaborate on the notion of balance (e.g. Mundy 2010; Kruis et al. 2015). This notion seems to cause more discussion, probably because it raises different interpretations. Some scholars question the term "balance" since it gives an image of "equal weight" (Kruis et al. 2015). A suggestion is to replace balance, or at least think of it as a "combination" of elements (ibid.; see also Henri 2006; Ylinen and Gullkvist 2012). Mundy (2010), for her part, questions the idea of balance as a static position. Instead, she suggests that balance should be regarded as an ongoing process of creating a "dynamic tension" (ibid.; see also Henri 2006).

\subsection{Theoretical approaches}

In our second extraction process, we also considered theories and theoretical approaches adopted in the reviewed articles. In some cases these were difficult to identify since they were not always clearly and explicitly declared. There were also different kinds of theories, covering a spectrum from broad overall theoretical perspectives to specific theoretical concepts. In a few articles, we could also see a combination of two theoretical approaches. In these cases, we chose the most prominent one.

In the reviewed articles, we identified four theoretical approaches that were used more than once. The contingency and paradox approach, discussed in Sect.2.3, were among those. The theories used were sometimes stated explicitly and sometimes revealed implicitly by the use of key concepts such as "contingent", "practices", or "capabilities". The results are presented in Table 4, together with some examples of articles.

The contingency approach stands out. It was adopted in 20 articles and is thus the most frequently used theory. Eight studies used a practice-oriented approach, whereas the dynamic capability theory occurred in four articles. A clear paradox approach, which has been suggested by several authors (e.g. Eisenhardt 2000; Lewis and Smith 2014; Gaim and Wåhlin 2016), was clearly used in two articles (Carter et al. 2013; 
Table 5 Theoretical questions at the intersection of management control and innovation

\begin{tabular}{lc}
\hline Theory approach & Underlying question \\
\hline Contingency approach & How can a MCS be designed to fit internal and external \\
& characteristics related to innovation (and thereby \\
& suppress tensions)? \\
Practice-oriented approach & How are management controls used and tensions \\
& experienced and dealt with in practice in innovative \\
& settings? \\
Dynamic capabilities approach & How can management control systems be used to create \\
& a dynamic capability of dealing with both innovation \\
Paradox approach & and control? \\
& How can competing demands of management control \\
& and innovation exist simultaneously? \\
\hline
\end{tabular}

Aubert et al. 2015). Besides these four theoretical approaches, a number of other theories were used as a theoretical lens in the articles, including motivation theory (Adler and Chen 2011), organization theory (Artto et al. 2011), management control theory (Ecker et al. 2013), innovation management theory (Breunig et al. 2014), and network theory (e.g. Revellino and Mouritsen 2009). In some articles, it was not possible to identify any specific theory or theoretical approach.

An attempt to describe how the four mentioned approaches address the question of tensions at the intersections of management control and innovation is presented in Table 5.

As clarified in Sect. 2.3, a contingency approach searches for an alignment between managerial decisions and internal and external contingency factors. The idea is that a "good fit" will remove tensions. In the context of management control and innovation, a contingency approach addresses the question of how to design a MCS which fits, for example, the characteristics of an innovative company or an innovative process (see Haustein et al. 2014 for a review). Studies that use a practice-oriented approach aim to investigate how management controls are used and how tensions are dealt with in a particular innovative setting. The focus is on practices which can be defined as activities that people within a specific setting do on a regular basis (see e.g. Akroyd and Maguire 2011). This type of studies rarely uses hypothesis for generating explanations and predictions (ibid.). Instead the try to uncover patterns of activities, often by using case studies and field research (e.g. Breunig et al. 2014). The dynamic capability approach, which can be argued to reflect a "both-and" perspective, has been used by, for example, Brühl et al. (2010). Referring to Teece et al. (1997), they describe dynamic capabilities as a firm's ability to use resources and competences to deal with changing environments. They further stress that dynamic capabilities are firm specific and embedded in processes and routines. Regarding management control and innovation, a dynamic capability can enable a firm to integrate these processes and to balance their competing demands in a competitive way. Mundy (2010), for example, stresses that a combination of different uses of management controls may create a dynamic tension and a unique organizational capability (see also Henri 2006). The paradox approach, lastly, has similarities with the dynamic capability approach since it assumes that tensions are fruitful and should not be suppressed. From a paradox 
perspective, a central question in the context of management control and innovation concerns how the competing demands that these two phenomena create can exist simultaneously. According to Gaim and Wåhlin (2016) this can be accomplished by rethinking the relationship between competing demands. By framing a tension between management control and innovation as a paradox, creative solutions to competing demands may be discovered; solutions which integrate and even reinforce competing demands (see e.g Aubert et al. 2015).

\subsection{The status of research on tensions at the intersection of MC and innovation}

Our review shows that the number of publications dealing with tensions at the intersection of management control and innovation increased during the review period, indicating an increased research interest in the topic. Although rarely studied in the 1990s, a handful of articles have been published each year since 2009. The reviewed articles are published in a variety of journals. However, journals in the areas of accounting and management control dominate, which may suggest that the question of tensions has particularly interested scholars within management control.

Among the reviewed articles, 40 were original ones presenting empirical findings and observations. The remaining seven articles were theoretical. This is an interesting finding, since the debate regarding tensions often seems to be a conceptual and ontological one. There is an ongoing discussion regarding, for example, the nature of tensions and how to respond to them, as well as the most fruitful theoretical approach to tensions. However, our analysis of the characteristics of the included studies reveals that the issue of tensions is also empirically driven. The results regarding methodological approaches and research strategies are also interesting, and they differ from the results of Davila, Foster and Oyon's (2009) literature review. Having reviewed articles on innovation and management control, they concluded that most empirical studies rely on cross-sectional survey research designs, primarily suited for testing hypotheses. In our review, 59\% of the empirical studies are based on a case-study strategy. One explanation for this difference may be that there has been a shift towards more case-based studies within the fields of management control and innovation in general in recent years. Another possible explanation is that we add the dimension of tension in our review. Researchers interested in tension-related issues may be more likely to use case studies. Or maybe a case-study methodology is more suitable when dealing with tensions, which, for example, Smith and Lewis (2011) suggest. Among the articles, the contingency approach was the most frequently used theoretical approach, which is in line with the results of, for example, Davila, Foster and Oyon's (2009) review. It indicates that contingency theory is still important when doing research at the intersection of management control and innovation. It was also used despite some criticism regarding its capacity to deal with tensions in a dynamic way (see e.g. Smith and Lewis 2011; Aubert et al. 2015).

Regarding tension-related terms, our review found that these were used in a variety of ways. The overall terms of "tension" and "balance", "paradox" and "trade-off" are the most commonly used. As Smith (2014) stresses and as our review indicates, the tension-related terms are often used interchangeably and without real consideration of their differences. 


\section{Tensions, competing demands and opposing elements}

\subsection{Type of tensions}

Since the reviewed articles varied in many respects, for example, in conceptual use, theoretical approaches, research purposes, and empirical investigations, they also approached tensions in many different ways. Inspired by Smith and Lewis's (2011) distinction between latent and salient tensions (see Sect.2.3), we started to think in terms of types of tensions. Our analysis then reveals that the authors use the notion of tension ${ }^{2}$ in several ways, reflecting contrasting meanings and types of tension. In one sense, it refers to a natural and embedded organizational tension. As mentioned in Sect. 2.3, these types of tensions are often labelled inherent organizational tensions (see e.g. Henri 2006; Hodgson and Briand 2013; Ylinen and Gullkvist 2014) or as in Smith and Lewis's model "latent tensions" (2011). Considering the focus of our review, an important inherent organizational tension, mentioned in many articles, is an inherent tension between innovation and control. Such tension is expressed in the quotation by Perez-Freije and Enkel (2007), which was mentioned in the introduction. It reads, "While some degree of freedom and flexibility is essential for productive innovation teams, management is faced with the challenge of instituting control mechanisms that lead projects in the right strategic direction..." (p. 11).

The idea of an inherent tension between innovation and control appears in most (at least 40) of the articles. It is expressed in various ways, depending, for example, on organizational level and focus of study. Therefore, it will be further elaborated on in the next Sect.5.2. This type of tension is often mentioned in the introduction as a way of introducing the research topic and arguing for its relevance. Sometimes it is only mentioned in the introduction and is not further elaborated on or returned to. None of the reviewed articles develop or present a more developed framework that captures different dimensions of inherent innovation-control tensions. When it comes to the inherent tensions, they often seem to be viewed as dualities or paradoxes, even if they are not always explicitly labelled as such. It means that they are often regarded as tensions that hold opposing and interrelated elements (Smith and Lewis 2011) and require responses that deal with both elements simultaneously. However, in some cases they also seem to be interpreted as trade-offs, suggesting a choice of different options on a continuum.

A second type of tension that is found in the articles relates to a management control tension, a tension that exists due to different and competing roles and uses of management controls. Sometimes this management control tension is depicted as an inherent organizational tension as well, in other words, as a natural tension that has to be dealt with. This is the case, for example, when Davila (2000) stresses the competing roles of management control systems, to reduce uncertainty and goal divergence at the same time (see also Akroyd and Maguire 2011; Artto et al. 2011). However, a more common way to describe management control tensions is to depict them as created tensions. From this view, management control tensions appear due to a com-

2 When we use "the notion of tension" we refer to the general idea of tension, irrespective of which tension-related term is actually used. 
bination of various elements and uses of management controls (see e.g. Henri 2006; Mundy 2010), for example, by combining formal and informal controls (e.g. Silaen and Williams 2009), or mechanistic and organic controls (e.g. Ylinen and Gullkvist 2012, 2014). In this context, the word "balance" (e.g. Mundy 2010) often occurs. A common idea seems to be that a good combination and a good balance of opposing elements of control can either reduce a tension or-as a somewhat different viewcreate a "dynamic tension" (see e.g. Mundy 2010). From a practical point of view, a crucial thing — when the ambition is to both demonstrate an innovation capacity and embrace formal controls (cf. Adler and Chen 2011, p. 64) - is then to combine various opposing control elements (see Sect. 5.3 for an elaboration on opposing management control elements). This type of created management control tension is conceptually elaborated on to a larger extent than the inherent ones. Therefore, discussions regarding this type of tension are found in the articles in conceptual and theoretical sections as well as in discussions and conclusions.

The third, less common, type of tension appears mainly in articles that adopt a practice-oriented approach. It represents specific tensions that practitioners (e.g. managers and product developers) confront in their decision-making about innovation and product development. Contrary to the inherent tensions, these can be regarded as social constructions since they are experienced by the actors (Smith and Lewis 2011). This type of tension is apparent in a handful of articles examining, for example, tensions between strategic goals (e.g. Jørgensen and Messner 2010), management accounting calculations (Mouritsen et al. 2009) or between quality and costs (Jeacle and Carter 2012). It seems to reflect an either-or approach more than previous types, suggesting an ongoing compromise between, for example, stakeholders' demands and different project targets. In some of these articles, the tensions are also explicitly discussed in terms of a trade-off (e.g. Jørgensen and Messner 2010) or a dilemma (e.g. Knardal and Pettersen 2015). Naturally, these tensions are mostly dealt with in case descriptions or similar.

\subsection{Categories of inherent innovation-control tensions}

As mentioned in the previous section, the inherent innovation-control tension is touched upon in most articles. Often it is captured by explicitly using the specific concepts of innovation and control and presenting them as opposing elements. However, the overall tension of innovation and control is also described in many supplementary ways, covering various aspects related to innovation and management control. When viewed together, the reviewed articles accentuate a disorganized variety regarding inherent innovation-control tensions. There are also few attempts to more conceptually organize the presented tensions. A greater conceptual clarity could therefore be desirable to enable more fruitful theoretical discussions and to guide future research (cf. Smith and Lewis 2011). One example of such a framework is found in the field of design management and in the article by Cautela and Zurlo (2011), in which they present a system of tensions faced by design managers. Here, then, we see a possibility for conceptual development based on our review and with a focus on inherent innovation-control tensions. 
Accordingly, we tried to see patterns among the described innovation-control tensions by relating them to the level of analysis. As stressed in Sect.2.3, several researchers have asked for such attempts. In Table 6, inherent innovation-control tensions are thus organized in terms of five levels and their related competing demands. They are further expressed in terms of opposing elements that reflect either an innovation or control element.

As the table reveals, innovation is expressed in terms of elements such as creativity, empowerment, uncertainty, freedom, flexibility, open boundaries and trust. The control element is captured in terms of efficiency, accountability, goal congruence, discipline, standardization and safeguarding. Similar to Smith and Lewis (2011), our analysis reveals that some opposing elements-or at least very similar opposing elements-occur at several levels. However, we can also see differences between the levels. Tensions that are mentioned at the unit/division level often address competing demands related to organizational design and management, reflected in opposing elements such as empowerment-accountability and autonomy-centralization. At the project level, the tension between uncertainty in new product development projects and goal congruence with the organization's financial and strategic goals, for example, is stressed (e.g. Akroyd and Maguire 2011; cf. also Davila 2000). Tensions presented at the interorganizational level focus on aspects related to collaboration and relational issues, such as trust and coordination. This level also addresses tensions related to openness versus closedness ("safeguarding”; e.g. Brattström and Richtnér 2014).

\subsection{Categories of management control tensions}

As previously stated (in Sect. 5.1), a number of articles deal with management control tensions. Having scrutinized these articles, we can conclude that the management control elements discussed and studied cover several management control dimensions. Accordingly — and similar to the inherent organizational tensions- the articles and presented studies vary with respect to management control dimensions. It further means that a wide range of management control frameworks (cf. e.g. Haustein et al. 2014) are adopted. The most commonly used framework is Simons' (1995) levers of control, primarily his ideas about interactive and diagnostic uses (e.g. Knardal and Pettersen 2015). Some studies take as their point of departure Adler and Borys' (1996) framework and their distinction between enabling and coercive controls (e.g. Mundy 2010) or Chenhall's (2003) mechanistic and organic controls (e.g. Ylinen and Gullkvist 2012, 2014). A number of authors also refer to Malmi and Brown (2008) and their ideas about "packages of controls".

With the aim of creating a synthesized picture of management control dimensions and associated tensions, we have categorized them into three areas: (1) types of controls, (2) purposes of controls, and (3) use of controls. In this work we were particularly inspired by the framework of Tessier and Otley (2012), as mentioned and briefly described in Sect. 2.1.

In Table 7, we have structured those management control tensions that are mentioned and sometimes also empirically studied in reviewed articles, in line with the three categories of management control dimensions. 


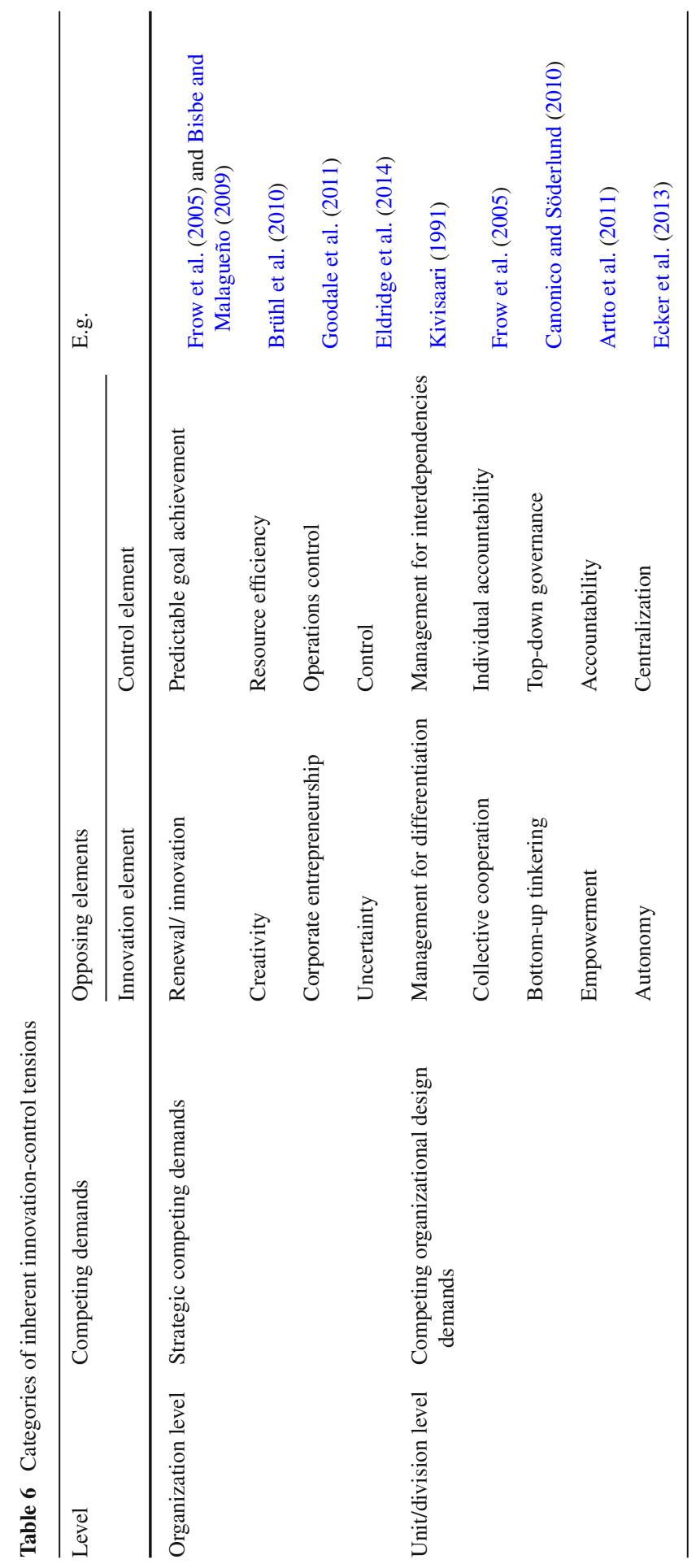




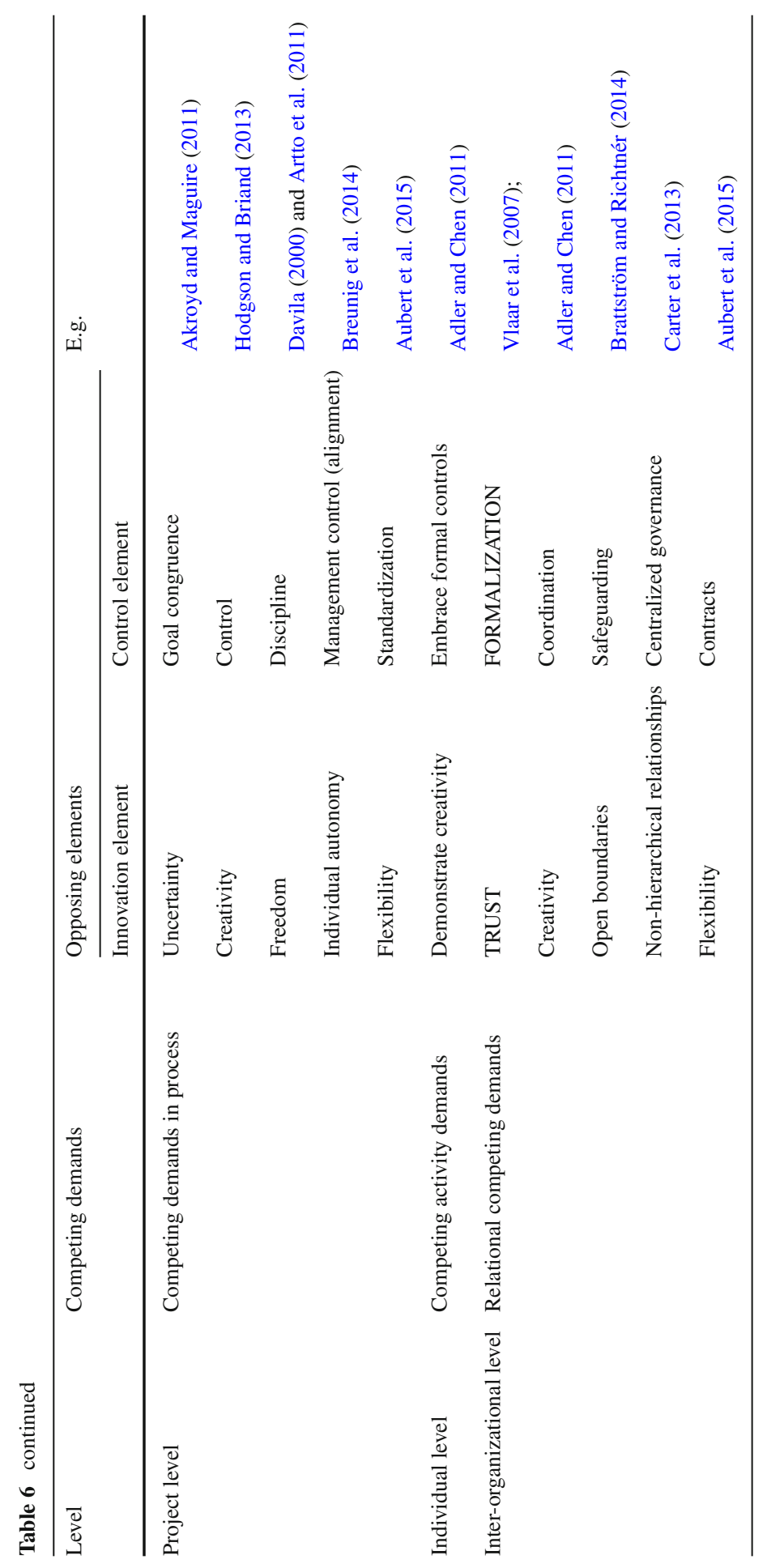


Table 7 Categories of management control tensions

\begin{tabular}{lll}
\hline MC dimension & Tension & E.g. \\
\hline Types of controls & Non-financial-financial controls & Davila (2000) \\
& Informal-formal controls & Silaen and Williams (2009) \\
& Organic-mechanistic controls & Ylinen and Gullkvist (2012) \\
& Trust-formal controls & Brattström and Richtnér (2014) \\
Purposes of controls & Pursue strategic & Frow et al. (2005) \\
& initiatives-implement strategies & \\
& Uncertainty reduction-goal & Akroyd and Maguire (2011) \\
& congruence & \\
& Build trust-safeguarding & Brattström and Richtnér (2014) \\
& Freedom-avoid opportunistic & Aubert et al. (2015) \\
Use of controls & Relational-instrumental & \\
& & Vosselman and van der \\
& Loose-tight & Meer-Kooistra (2009) \\
& Enabling-coercive & Davila et al. (2009) \\
& Interactive-diagnostic & Mundy (2010) \\
& & Artto et al. (2011)
\end{tabular}

As shown in the table, the reviewed articles address several management control dimensions and cover many different tensions, most of them mentioned above. Of the three categories, tensions related to types and use of controls are most frequently elaborated on. The category of control purposes is not so well represented. Among the specific tensions, the tension reflected in a combination of interactive and diagnostic uses is the one that is discussed and studied the most. How the presented tensions are approached by the authors and in empirical studies depends upon the theoretical perspective adopted.

\subsection{A tension-based framework}

Based on both previous research in general and on the specific results of our literature review, we present a tension-based framework in Table 8. The framework summarizes the discussions regarding tensions in the following aspects: actor perspective, type of tension, theoretical approach, interpretation and response. The presented framework could be seen as an attempt to create some form of unifying platform, which Smith and Lewis (2011) ask for. They argue that such a platform can "spur continued theoretical debate and guide future empirical research" (p. 397).

To start with, the framework distinguishes between two different actor perspectives on tensions. These actor perspectives are based on the theoretical Sect. 2.3, and are further developed in Sect. 5.1. The researcher's perspective addresses tensions as they are approached and conceptually developed by researchers. The practitioner's perspective, on the other hand, refers to tensions as they are experienced, dealt with and expressed by practitioners. To continue, the researcher's perspective involves three types of tensions, previously described in Sect.5.1. They are (1a) inherent innovation-control 


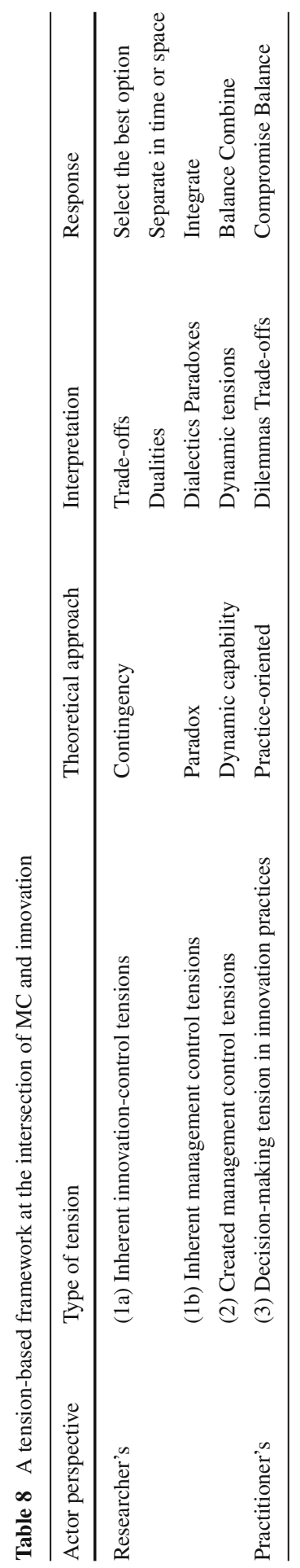


tensions, (1b) inherent management control tensions, and (2) created management control tensions. As can be seen, the framework does not fully separate inherent innovation-control tensions and inherent management control tensions since both are depicted as tensions that exist naturally in the organization. The practitioner's perspective reflects a fourth type of tension, that is, decision-making tensions that practitioners face in, for example, innovation processes. Accordingly, by specifying several types of tensions and by relating them to two actor perspectives we refine Smith and Lewis's (2011) distinction between latent and salient tensions.

The third column in the framework presents the four theoretical approaches that we identified in our review. They are linked back to type of tension, as well as associated with different interpretations and responses to tensions. The theoretical approach can thus be seen as an element which links the left part of the table with the right one. Inherent innovation control tensions and inherent management control tensions are primarily studied and discussed by using either a contingency or a paradox approach. The idea of a created management control tension occurs in articles which are based on a dynamic capability approach. The last type of tension is addressed primarily in studies that use a practice-oriented theoretical approach.

The fourth column in the framework presents different interpretations and conceptualizations of tensions, whereas the fifth column suggests some responses to tensions. Both these elements are dependent on the theoretical perspective. From a contingency perspective, tensions seem mostly interpreted as trade-offs or dualities. Interpreted as a trade-off, a relevant response to a tension is to select the option that best fits the situation. When interpreted as a duality, a suggested response is to separate competing demands either in space or in time. Brattström and Richtnér (2014), for example, suggest that the responsibility of formal controls should be assigned to a department other than the one that performs it. They call this separation in space a "good copbad cop strategy". From a paradox perspective, inherent organizational tensions are interpreted as paradoxes or dialectics. It means that tensions are composed of competing demands that exist simultaneously and persist over time (cf. Aubert et al. 2015). Here, one suggested response which occurs in the articles is to integrate opposing elements, for example, by using management accounting or management control systems as "integration tools" (e.g. Brühl et al. 2010; Knardal and Pettersen 2015) or as "mediating instruments" (e.g. Jeacle and Carter 2012; Pärl 2014). The type of tension that we call a "created management control tension" is often discussed in terms of a dynamic tension. Here, the idea is to create a tension by balancing or combining different types, purposes or uses of controls (e.g. Henri 2006; Mundy 2010; Ylinen and Gullkvist 2014). Finally, the "decision-making tension in innovation practices", which is the fourth type of tension, is interpreted as trade-offs and dilemmas since they seem to entail an ongoing compromise for actors and departments and between, for example, competing goals.

\section{Conclusions}

This paper has presented a literature review of articles and studies dealing with tensions at the intersection of management control and innovation. One purpose of the paper 
has been to present the status of the research in the area in terms of types of articles, research methods, theoretical approaches, and tension-related terms used. Our review shows an increase in the number of publications during the review period, indicating an increased interest in the topic. However, the number of published articles is still small. Since 2009, a handful of articles have been published each year. Our literature review further reveals that the issue of tensions is not only of theoretical interest, since original articles, presenting some empirical findings and observations, dominated. Based on our review process, we can also conclude that a qualitative methodology and case-study research are commonly used in the empirical studies. Further, the contingency approach is still an important theoretical approach in research on management control and innovation (cf. Davila et al. 2009), and also when adding the aspect of tension. Regarding tension-related terms, our review shows that many terms are used in the articles, often interchangeably and without really clarifying their definitions. In other words, there is some confusion and ambiguity regarding the terms (cf. Smith and Lewis 2011).

This part of the review contributes to research on management control and innovation by providing an updated and tension-focused picture of the research status. It also brings some suggestions for future research. Considering the dominance of the contingency approach, there is a need to develop the notion of tensions from other theoretical perspectives and in relation to different tension-related terms. There are some articles that (conceptually and profoundly) elaborate on tensions from a paradoxical perspective (e.g. Gaim and Wåhlin 2016). Similar elaborations could be done from other theoretical perspectives. What does it mean to approach tensions from a dynamic capability perspective, for example? There is also a need to empirically study tensions at the intersection of management control and innovation using other theories and theoretical approaches than the contingency one. Empirical studies that are based on a clear paradox approach, for example, are rare, despite the fact that it has been claimed to be a fruitful approach when studying tensions (e.g. Gaim and Wåhlin 2016). Another suggestion for further research is to incorporate the employee perspective using a practice-oriented approach. How do employees perceive tensions between management control and innovation as well as the managers' way of dealing with them?

A second purpose of the paper was to compare the use and interpretations of tension in the reviewed articles, as well as to systematically map and categorize highlighted competing demands. In this analysis work, we draw on more general research and conceptualizations regarding tensions, management control and innovation. Through the analysis we identified four types of tensions: (1) inherent innovation-control tensions, (2) inherent management control tensions, (3) created management control tensions, and finally (4) decision-making tensions in innovation practices. The inherent and practice-oriented tensions have similarities with Smith and Lewis's (2011) latent and salient tensions. Latent tensions - or inherent tensions - exist naturally in organizational processes due to, for example, complexity, whereas the salient ones are experienced by organizational actors (ibid.). We have also initiated a categorization of inherent innovation-control tensions based on different organizational levels and related competing demands, in line with Aubert et al. (2015) suggestion. Inspired by Tessier and Otley (2012), we further present a categorization of management control tensions in terms of (1) types of controls, (2) purposes of controls, and (3) use of 
controls. Lastly, we have suggested a tension-based framework that holds actor perspective, type of tension and related theory approaches, as well as interpretations of and responses to tensions at the intersection of management control and innovation.

In doing the above and by developing two categorizations and a framework, we contribute to the literature by systematically organizing tensions at the intersection of management control and innovation. Hereby, we also enable a more precise debate on tensions. From a practical point of view, our framework makes a contribution by suggesting solutions to different types of tensions. It also clarifies the link between theoretical approaches, interpretations of tensions and responses to tensions. Our categorizations further point at some possibilities for future empirical studies. The categorization of inherent innovation-control tensions indicates that there are several organizational levels that can be in focus. Davila et al. (2009) argue that the organizational level is too aggregated to allow for an understanding of the relationship between management control and innovation. One suggestion for further research could therefore be to conduct studies at other levels. Since innovation processes and activities are often described as interactive, a focus on the interorganizational level and on relational competing demands could be one fruitful alternative. Further, both categorizations hold a number of tensions and opposing elements, which could be more closely looked into. Regarding, for example, use of controls, the balance between interactive and diagnostic uses has been quite well researched. The tight-loose dimension, as one example, has not been studied to the same extent.

The findings of our paper and study have some limitations, which give further suggestions for future research. Some limitations are related to our literature review. Although we have tried to capture all articles dealing with the subject according to our inclusion criteria, we have probably missed relevant articles. Selected keywords may, for example, have favoured articles in the area of management control. Additional reviews using other search strategies would therefore be a possibility for future studies. With the ambition to get an overall picture of the ongoing debate on tensions at the intersection of management control and innovation, we made a broad review. Because of this ambition, together with the limited number of reviewed articles (47 articles), our integrated framework should be regarded as a tentative one. Some interpretations and suggestions are based on quite a small number of observations. A closer look at and analysis of some selected parts of the framework could be one way of refining and developing the framework.

Open Access This article is distributed under the terms of the Creative Commons Attribution 4.0 International License (http://creativecommons.org/licenses/by/4.0/), which permits unrestricted use, distribution, and reproduction in any medium, provided you give appropriate credit to the original author(s) and the source, provide a link to the Creative Commons license, and indicate if changes were made.

\section{Appendix 1}

See Table 9. 


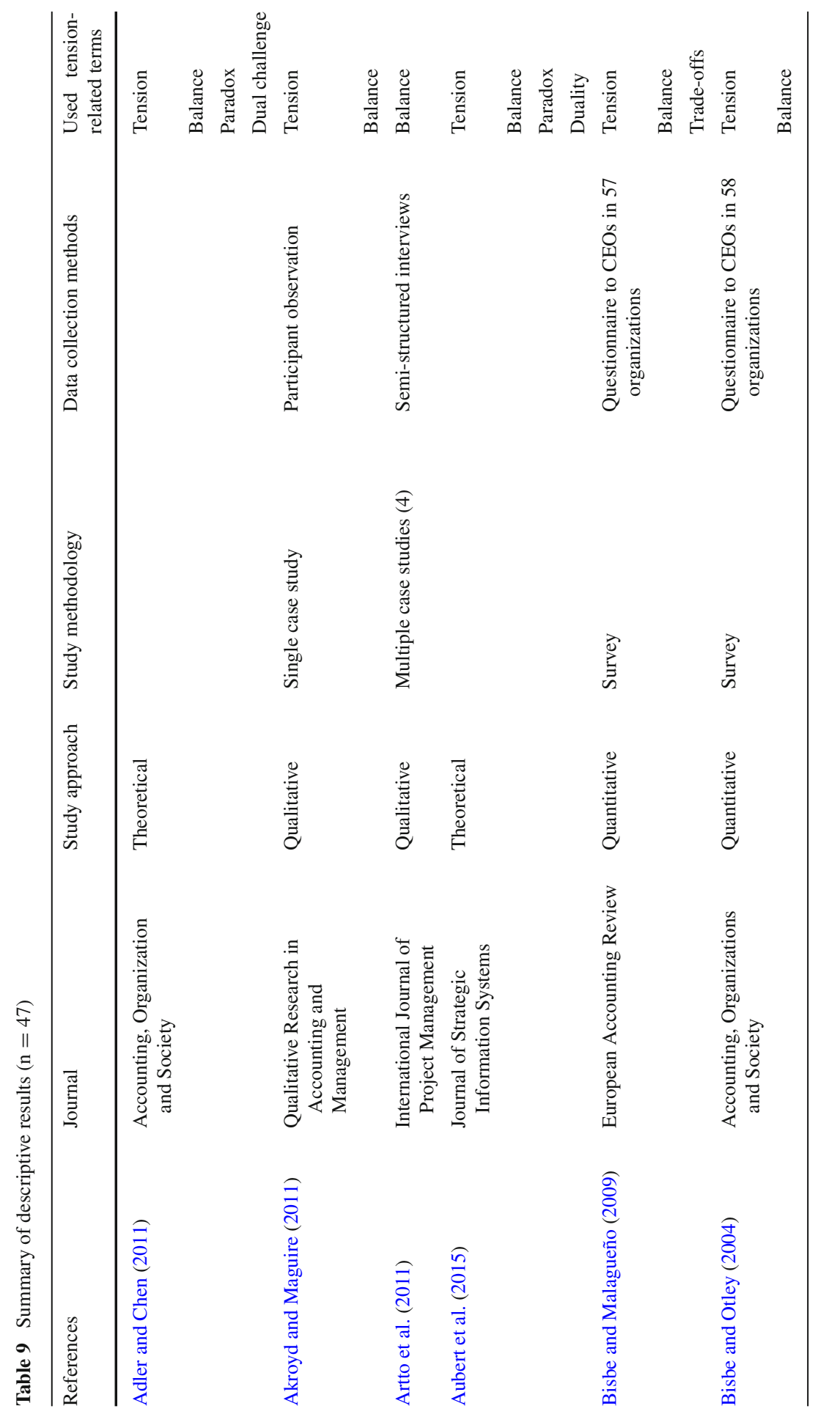




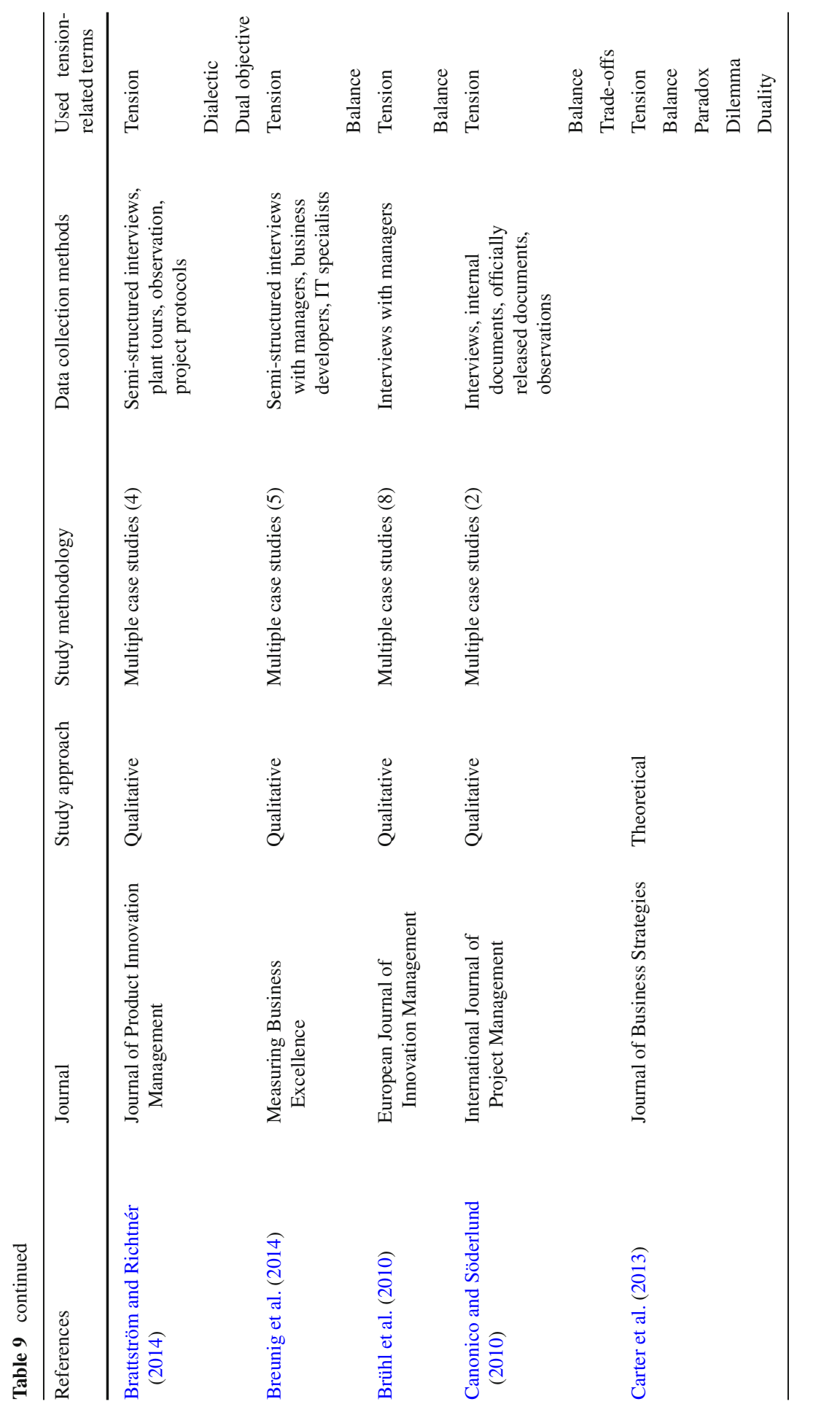




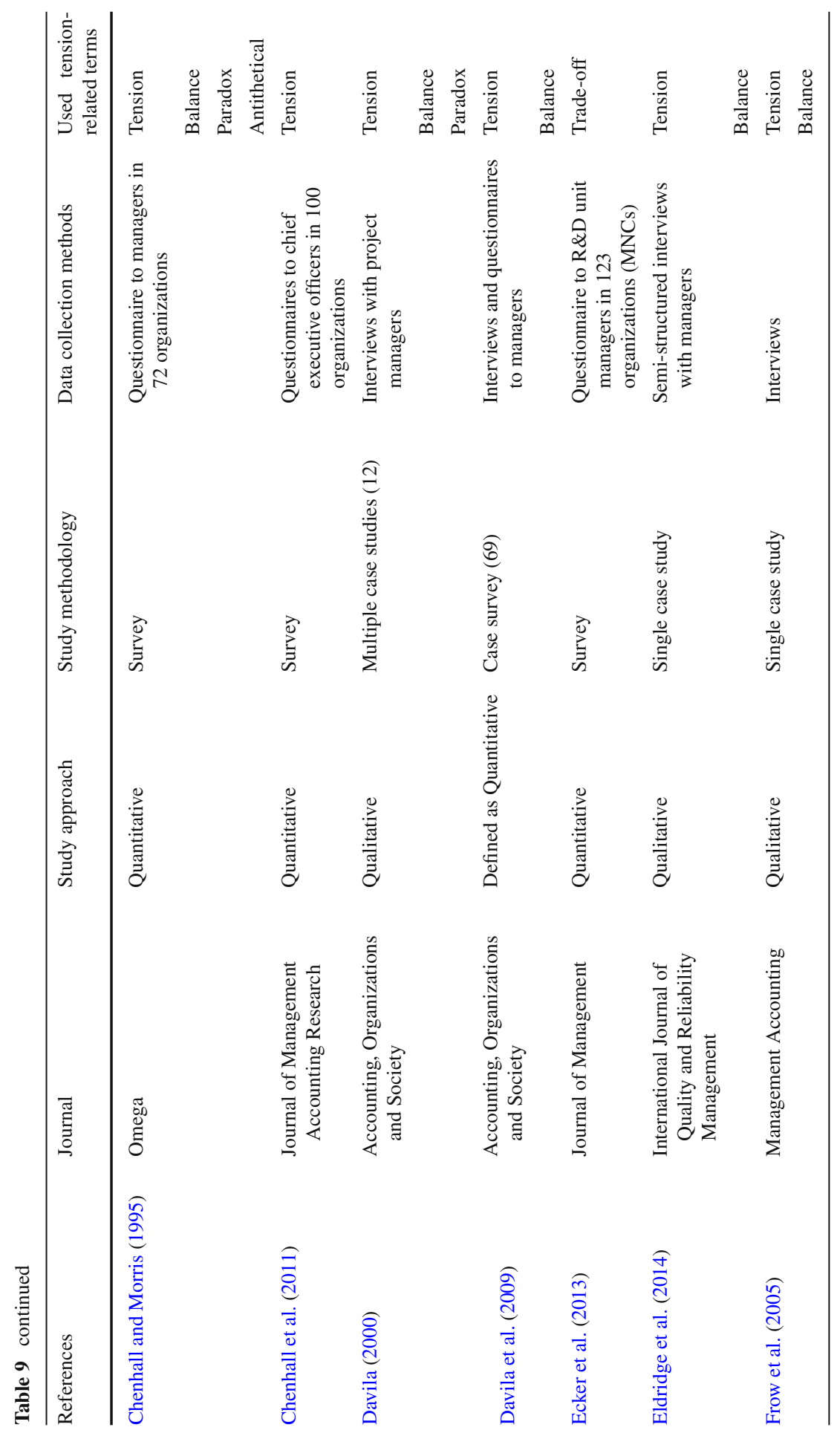




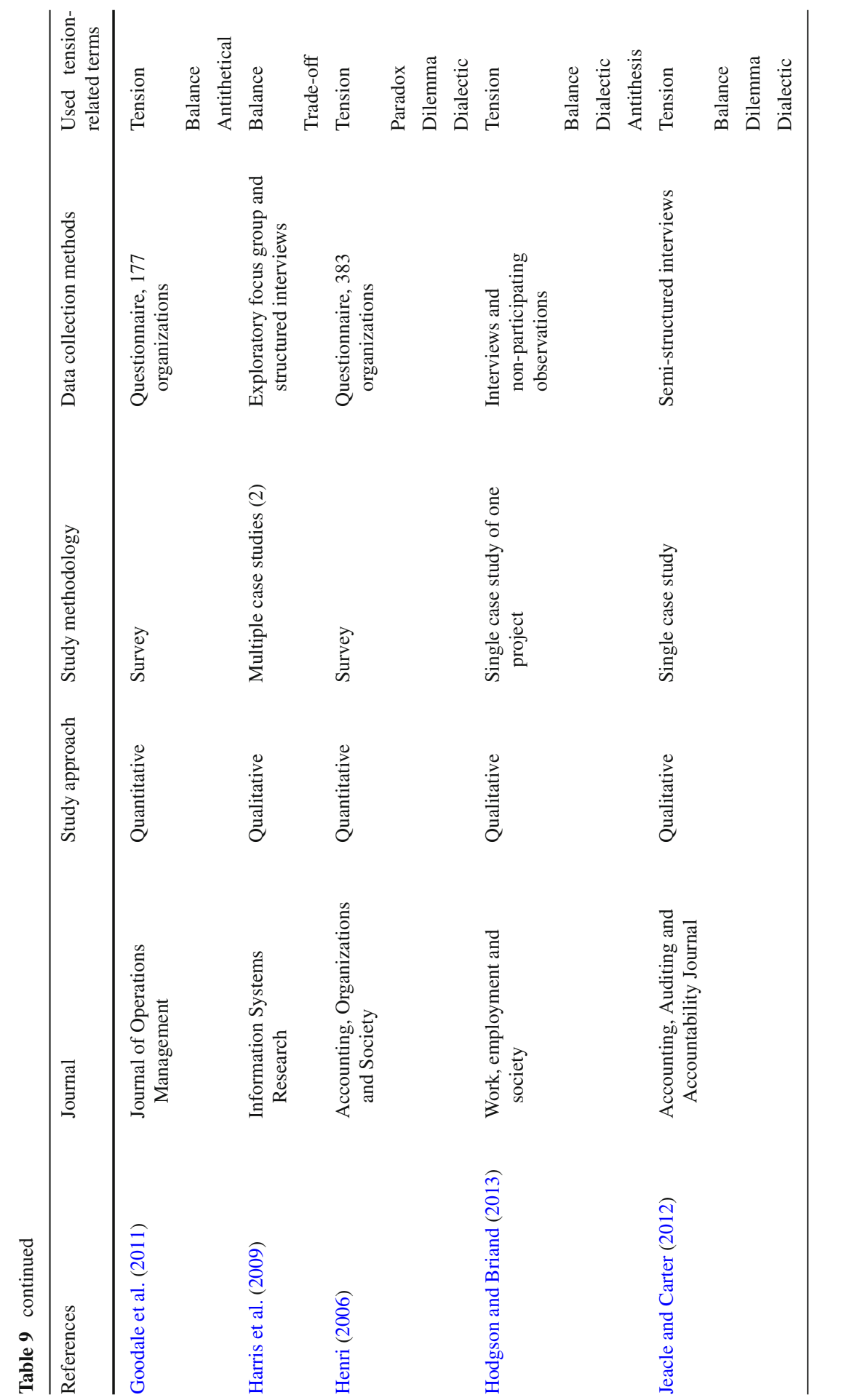




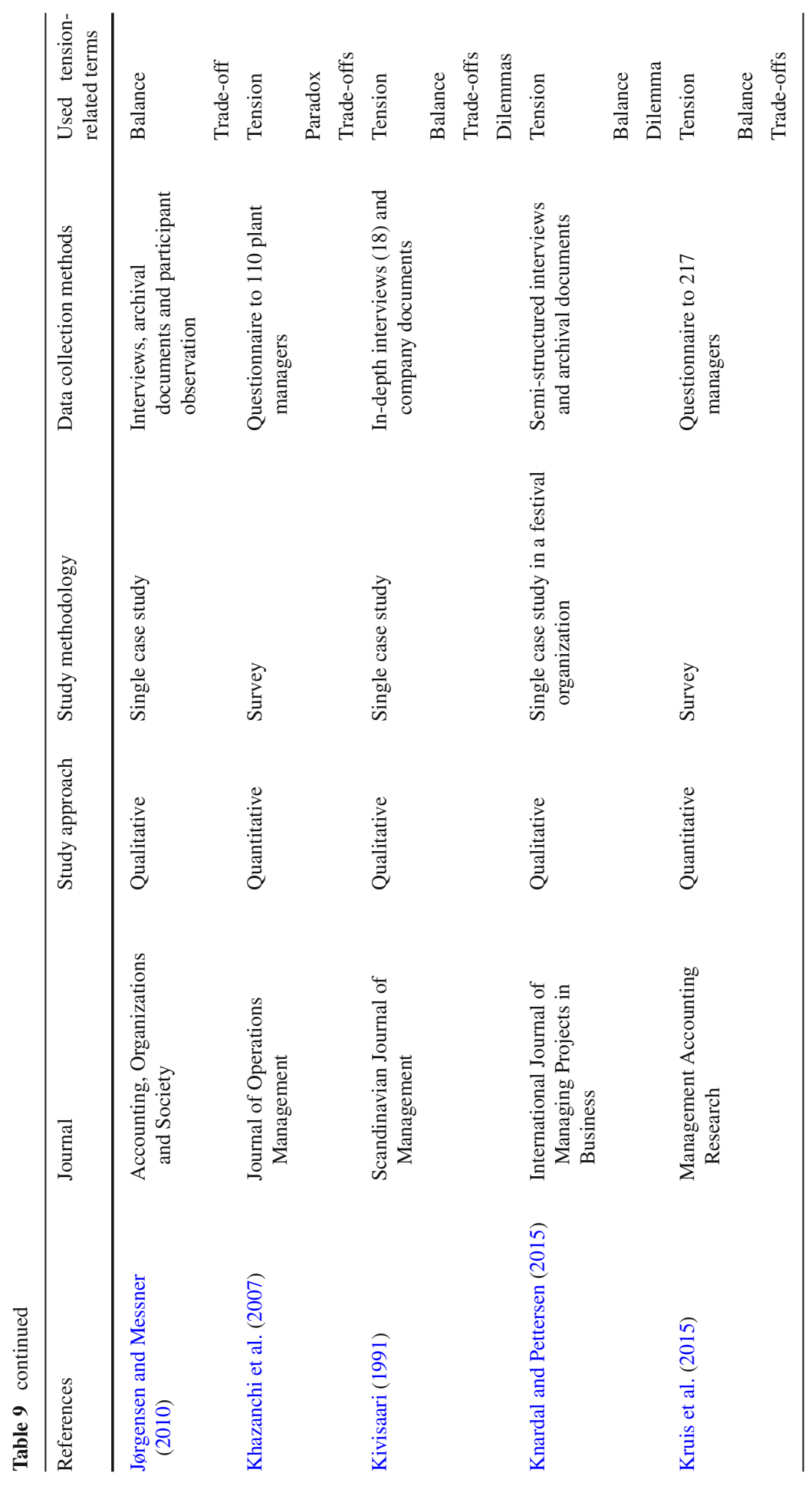




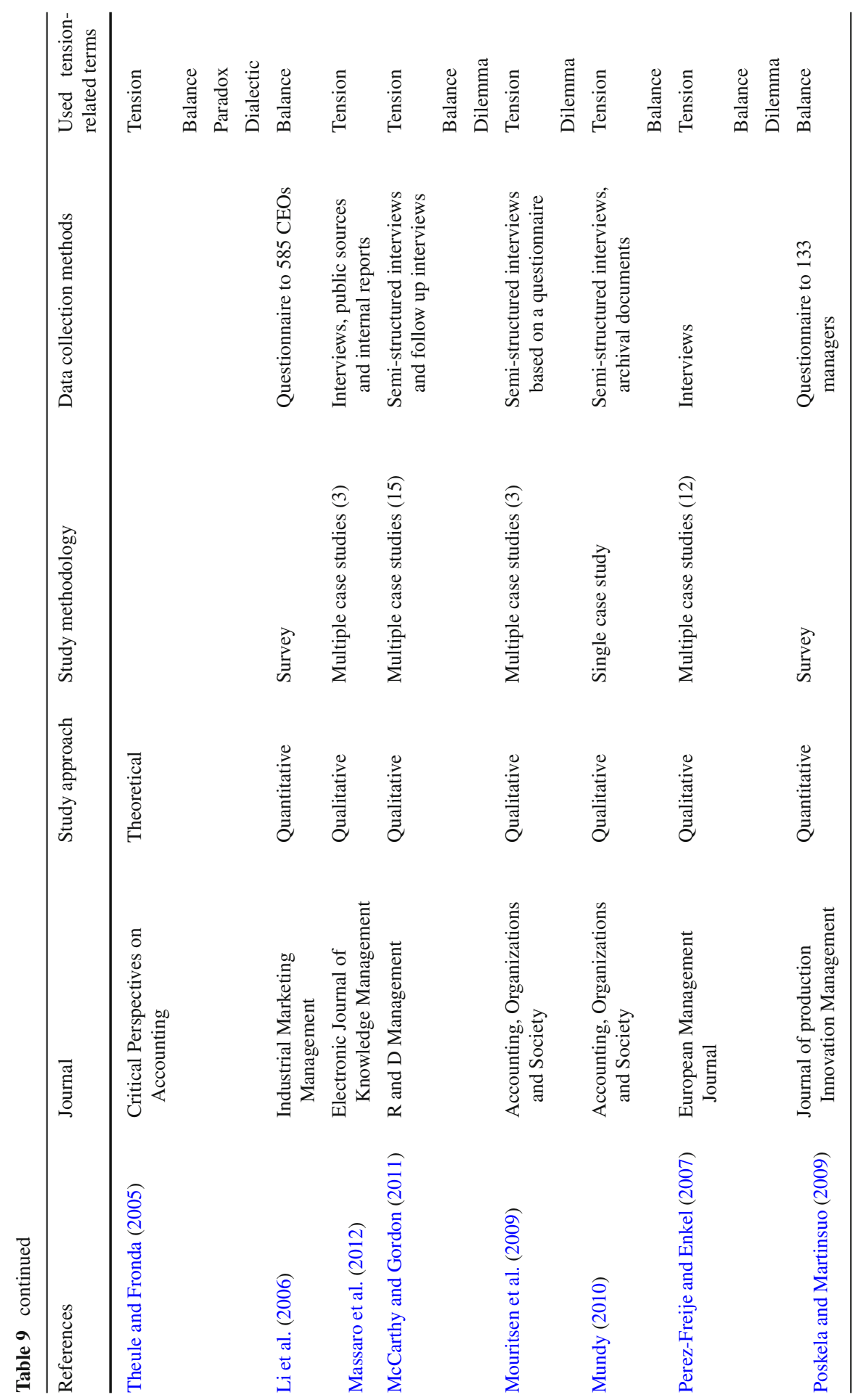




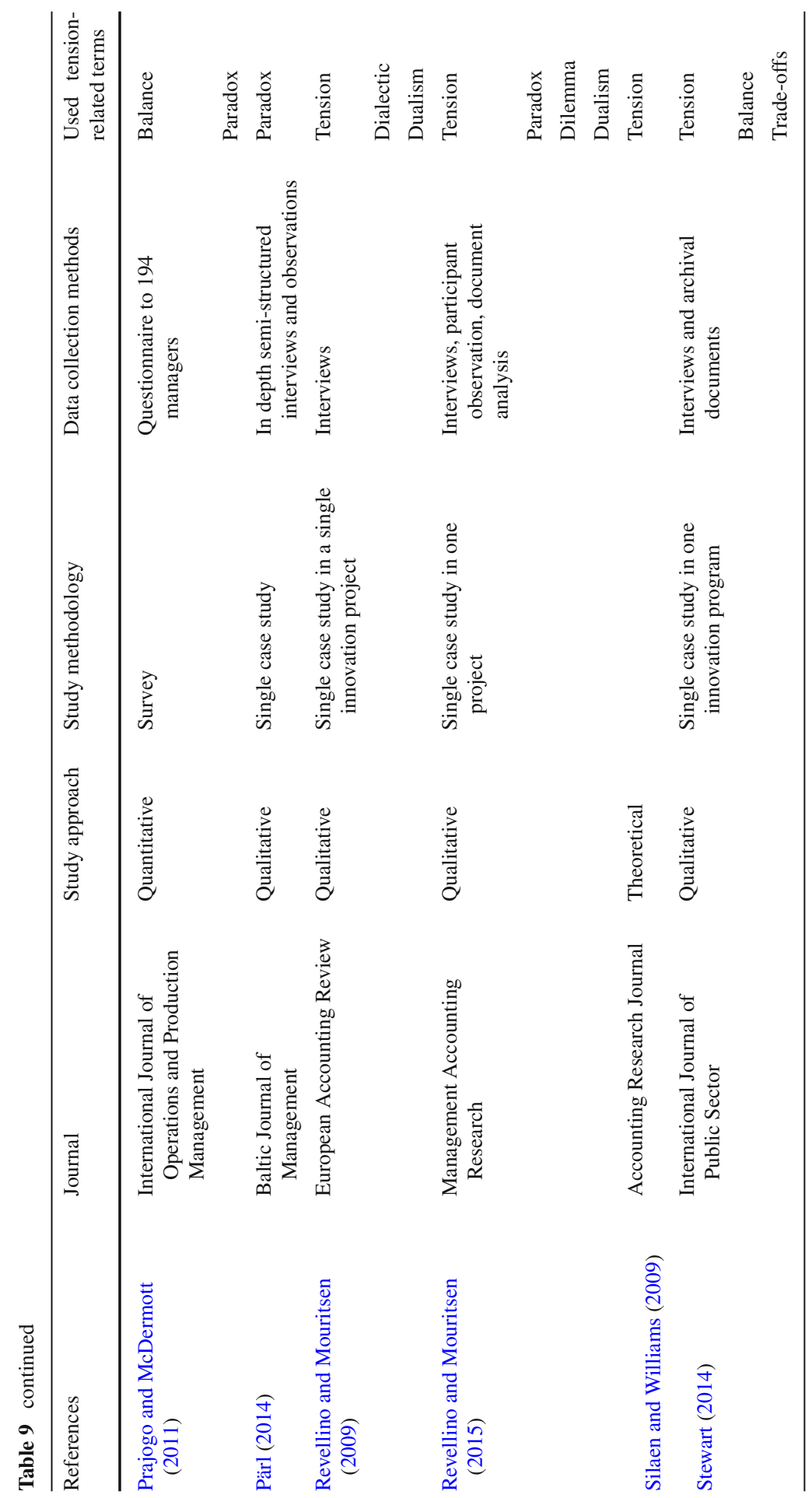




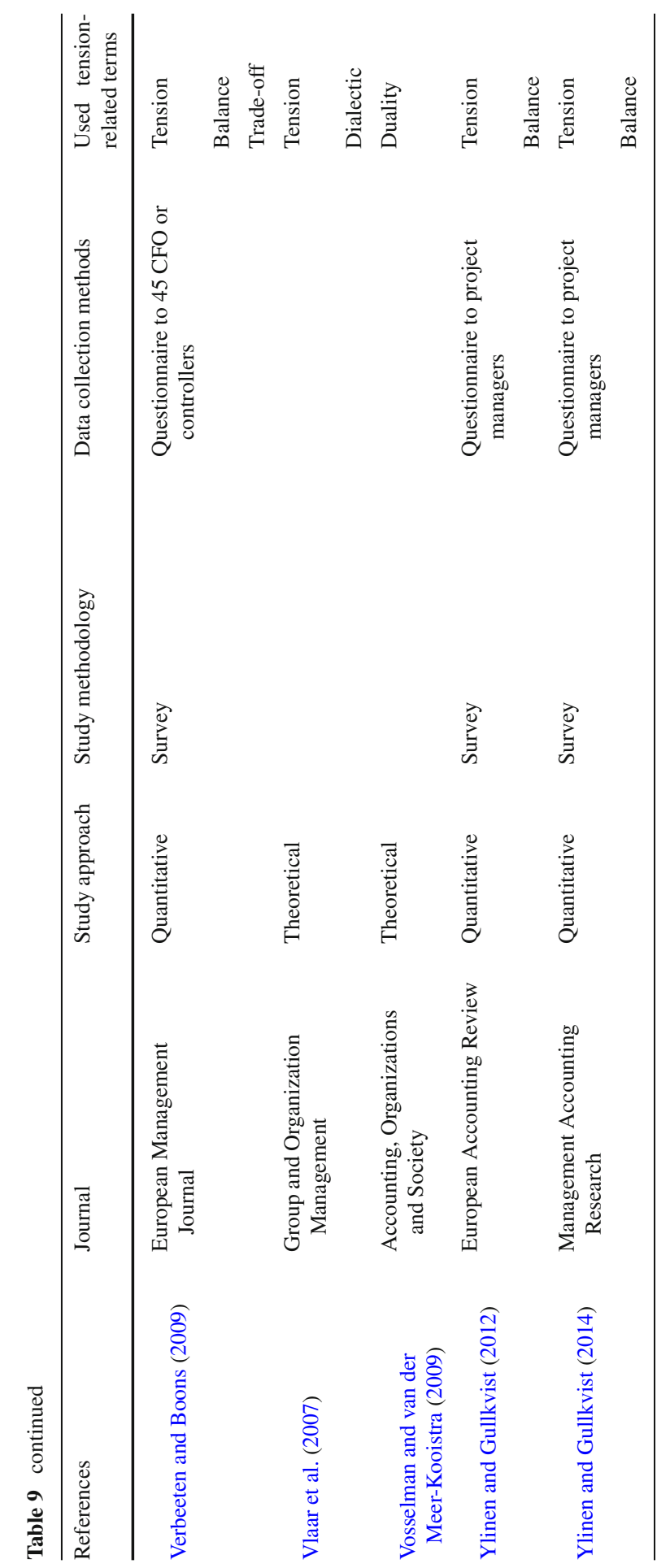




\section{Appendix 2}

See Table 10 .

Table 10 List of reviewed journal and number of analysed articles in each

\begin{tabular}{|c|c|}
\hline Name of journal & No. of identified articles $(n=47)$ \\
\hline Accounting, Auditing and Accountability Journal & 1 \\
\hline Accounting, Organizations and Society & 9 \\
\hline Accounting Research Journal & 1 \\
\hline Baltic Journal of Management & 1 \\
\hline Critical Perspectives on Accounting & 1 \\
\hline Electronic Journal of Knowledge Management & 1 \\
\hline European Accounting Review & 3 \\
\hline European Journal of Innovation Management & 1 \\
\hline European Management Journal & 2 \\
\hline Group and Organization Management & 1 \\
\hline Industrial Marketing Management & 1 \\
\hline Information Systems Research & 1 \\
\hline International Journal of Managing Projects in Business & 1 \\
\hline International Journal of Operations and Production Management & 1 \\
\hline International Journal of Quality and Reliability Management & 2 \\
\hline International Journal of Project Management & 1 \\
\hline International Journal of Public Sector Management & 1 \\
\hline Journal of Business Strategies & 1 \\
\hline Journal of Management & 1 \\
\hline Journal of Management Accounting Research & 1 \\
\hline Journal of Operations Management & 2 \\
\hline Journal of Product Innovation Management & 2 \\
\hline Journal of Strategic Information Systems & 1 \\
\hline Management Accounting Research & 4 \\
\hline Omega & 1 \\
\hline Qualitative Research in Accounting and Management & 1 \\
\hline $\mathrm{R}$ and $\mathrm{D}$ Management & 1 \\
\hline Scandinavian Journal of Management & 1 \\
\hline Work, Employment and Society & 1 \\
\hline
\end{tabular}

\section{References}

Achtenhagen, L., \& Melin, L. (2003). Managing the homogeneity-heterogeneity duality. In A. M. Pettigrew, et al. (Eds.), Innovative forms of organizing. London: SAGE Publications.

Adams, R., Bessant, J., \& Phelps, R. (2006). Innovation management measurement: A review. International Journal of Management Reviews, 8(1), 21-47. 
Adler, P. S., \& Borys, B. (1996). Two types of bureaucracy: Enabling and coercive. Administrative Science Quarterly, 41(1), 61-89.

Adler, P. S., \& Chen, C. X. (2011). Combining creativity and control: Understanding individual motivation in large-scale collaborative creativity. Accounting, Organizations and Society, 36, 63-85.

Ahrens, T., \& Chapman, C. S. (2004). Accounting for flexibility and efficiency: A field study of management control systems in a restaurant chain. Contemporary Accounting Research, 21(2), 271-301.

Akroyd, C., \& Maguire, W. (2011). The roles of management control in a product development setting. Qualitative Research in Accounting and Management, 8(3), 212-237.

Alvesson, M., \& Kärreman, D. (2004). Interfaces of control. Technocratic and socio-ideological control in global management consultancy firm. Accounting, Organizations and Society, 29, 423-444.

Artto, K., Kulvik, I., Poskela, J., \& Turkulainen, V. (2011). The integrative role of the project management office in the front end of innovation. International Journal of Project Management, 29, 408-421.

Aubert, B. A., Kishore, R., \& Iriyama, A. (2015). Exploring and managing the "innovation through outsourcing" paradox. Journal of Strategic Information Systems, 24, 255-269.

Baregheh, A., Rowley, J., \& Sambrook, S. (2009). Towards a multidisciplinary definition of innovation. Management Decision, 47(8), 1323-1339.

Barnson, S. C. (2014). Toward a theory of coaching paradox. Quest, 66(4), 371-384.

Bedford, D. S. (2015). Management control systems across different modes of innovation: Implications for firm performance. Management Accounting Research, 28, 12-30.

Bisbe, J., \& Malagueño, R. (2009). The choice of interactive control systems under different innovation management modes. European Accounting Review, 18(2), 371-405.

Bisbe, J., \& Otley, D. (2004). The effects of the interactive use of management control systems on product innovation. Accounting, Organizations and Society, 29(8), 709-737.

Brattström, A., \& Richtnér, A. (2014). Good cop-bad cop: Trust, control, and the lure of integration. Journal of Product Innovation Management, 31(3), 584-598.

Breunig, K. J., Aas, T. H., \& Hydle, K. M. (2014). Incentives and performance measures for open innovation practices. Measuring Business Excellence, 18(1), 45-54.

Brühl, R., Horch, N., \& Osann, M. (2010). Improving integration capabilities with management control. European Journal of Innovation Management, 13(4), 385-408.

Canonico, P., \& Söderlund, J. (2010). Getting control of multi-project organizations: Combining contingent control mechanisms. International Journal of Project Management, 28, 796-806.

Carter, W. R., Davis, P. E., Herchen, J. L., \& Chandna, V. (2013). Pitfalls and paradoxes: Coping with the capabilities-rigidities dilemma in whole networks. Journal of Business Strategies, 30(2), 97-119.

Cautela, C., \& Zurlo, F. (2011). Managing the five tensions of the design process. Design Management Review, 22(3), 6-14.

Chenhall, R. H. (2003). Management control systems design within its organizational context: Findings from contingency-based research and directions for the future. Accounting, Organizations and Society, 28(2-3), 127-168.

Chenhall, R. H., Kallunki, J.-P., \& Silvola, H. (2011). Exploring the relationships between strategy, innovation, and management control systems: The roles of social networking, organic innovative culture, and formal controls. Journal of Management Accounting Research, 23, 99-128.

Chenhall, R. H., \& Morris, D. (1995). Organic decision and communication processes and management accounting systems in entrepreneurial and conservative business organizations. Omega, 23(5), 485497.

Chiesa, V., Frattini, F., Lamberti, L., \& Noci, G. (2009). Exploring management control in radical innovation projects. European Journal of Innovation Management, 12(4), 416-443.

Cooper, H. (2009). Research synthesis and meta-analysis—a step-by-step approach. Applied social research methods series (Vol. 2). Thousand Oaks: SAGE.

Crossan, M. M., \& Apaydin, M. (2010). A multi-dimensional framework of organizational innovation: A systematic review of the literature. Journal of Management Studies, 47(6), 1154-1191.

Davila, T. (2000). An empirical study on the drivers of management control systems' design in new product development. Accounting, Organizations and Society, 25(4), 383-409.

Davila, T., Foster, G., \& Li, M. (2009). Reasons for management control systems adoption: Insights from product development systems choice by early-stage entrepreneurial companies. Accounting, Organizations and Society, 34(3), 322-347.

Davila, T., Foster, G., \& Oyon, D. (2009). Accounting and control; entrepreneurship and innovation: Venturing into new research opportunities. European Accounting Review, 18(2), 281-311. 
Ecker, B., van Triest, S., \& Williams, C. (2013). Management control and the decentralization of R\&D. Journal of Management, 39(4), 906-927.

Eisenhardt, K. M. (2000). Paradox, spirals, ambivalence: The new language of change and pluralism. Academy of Management Review, 25(4), 703-705.

Eisenhardt, K. M., Furr, N. R., \& Bingham, C. B. (2010). Microfoundations of performance: Balancing efficiency and flexibility in dynamic environments. Organization Science, 21(6), 1263-1273.

Eldridge, S., van Iwaarden, J., van der Wiele, T., \& Williams, R. (2014). Management control systems for business processes in uncertain environments. International Journal of Quality and Reliability Management, 31(1), 66-81.

Francis, D., \& Bessant, J. (2005). Targeting innovation and implications for capability development. Technovation, 25, 171-183.

Frow, N., Marginson, D., \& Ogden, S. (2005). Encouraging strategic behaviour while maintaining management control: Multi-functional project teams, budgets, and the negotiation of shared accountabilities in contemporary enterprises. Management Accounting Research, 16(3), 269-292.

Gaim, M., \& Wåhlin, N. (2016). In search of a creative space: A conceptual framework of synthesizing paradoxical tensions. Scandinavian Journal of Management, 32, 33-44.

Goodale, J. C., Kuratko, D. F., Hornsby, J. S., \& Covin, J. G. (2011). Operations management and corporate entrepreneurship: The moderating effect of operations control on the antecedents of corporate entrepreneurial activity in relation to innovation performance. Journal of Operations Management, 29, 116-127.

Harris, M. L., Collins, R. W., \& Hevner, A. R. (2009). Control of flexible software development under uncertainty. Information Systems Research, 20(3), 400-419.

Haustein, E., Luther, R., \& Schuster, P. (2014). Management control systems in innovation companies: A literature based framework. Journal of Management Control, 24, 343-382.

Henri, J.-F. (2006). Management control systems and strategy: A resource-based perspective. Accounting, Organization and Society, 31(6), 529-558.

Hodgson, D., \& Briand, L. (2013). Controlling the uncontrollable: 'Agile' teams and illusions of autonomy in creative work. Work, employment and society, 27(2), 308-325.

Janssen, S., Moeller, K., \& Schlaefke, M. (2011). Using performance measures conceptually in innovation control. Journal of Management Control, 22, 107-128.

Janssens, M., \& Steyaert, C. (1999). The world in two and a third way out? The concept of duality in organization theory and practice. Scandinavian Journal of Management, 15(2), 121-139.

Jeacle, I., \& Carter, C. (2012). Fashioning the popular masses: Accounting as mediator between creativity and control. Accounting, Auditing and Accountability Journal, 25(4), 719-751.

Jørgensen, B., \& Messner, M. (2010). Accounting and strategizing: A case study from new product development. Accounting, Organizations and Society, 35, 184-204.

Khazanchi, S., Lewis, M. W., \& Boyer, K. K. (2007). Innovation-supportive culture: The impact of organizational values on process innovation. Journal of Operations Management, 25, 871-884.

Kivisaari, S. (1991). Management of innovation in the modern corporation: Dilemmas in the corporate control of R\&D. Scandinavian Journal of Management, 7(3), 219-228.

Knardal, P. S., \& Pettersen, I. J. (2015). Creativity and management control: The diversity of festival budgets. International Journal of Managing Projects in Business, 8(4), 679-696.

Kruis, A-M., Speklé, R. F., \& Widener, S. K. (2015). The levers of control framework: An exploratory analysis of balance. Management Accounting Research,(In press)

Le Theule, M. A., \& Fronda, Y. (2005). The organization in tension between creation and rationalization: Facing management views to artistic and scientific creators. Critical Perspectives on Accounting, 16, 749-786.

Lewis, M. W., \& Smith, W. K. (2014). Paradox as a metatheoretical perspective: Sharpening the focus and widening the scope. The Journal of Applied Behavioural Science, 50(2), 127-149.

Li, Y., Liu, Y., \& Zhao, Y. (2006). The role of market and entrepreneurship orientation and internal control in the new product development activities of Chinese firms. Industrial Marketing Management, 35, 336-347.

Lueg, R., \& Radlach, R. (2016). Managing sustainable development with management control systems: A literature review. European Management Journal, 34, 158-171.

Lövstål, E. (2008). Management Control Systems in Entrepreneurial Organisations-A Balancing Challenge. Ph.D .Thesis, Jönköping: Jönköping International Business School. 
Magnusson, M., Boccardelli, P., \& Börjesson, S. (2009). Managing the efficiency-flexibility tension in innovation: Strategic and organizational aspects. Creativity and Innovation Management, 18(1), 2-7.

Malmi, T., \& Brown, D. A. (2008). Management control systems as a package-opportunities, challenges and research directions. Management Accounting Research, 19(4), 287-300.

Massaro, M., Bardy, R., \& Pitts, M. (2012). Supporting creativity through knowledge integration during the creative processes. A management control system perspective. Electronic Journal of Knowledge Management, 10(3), 258-267.

McCarthy, I. P., \& Gordon, B. R. (2011). Achieving contextual ambidexterity in R\&D organizations: A management control system approach. $R \& D$ Management, 41(3), 240-258.

Merchant, K., \& Van der Stede, W. (2012). Management control systems: Performance measurement, evaluation and incentives. Harlow: Pearson Education.

Mouritsen, J., Hansen, A., \& Hansen, C. Ø. (2009). Short and long translations: Management accounting calculations and innovation management. Accounting, Organizations and Society, 34, 738-754.

Mundy, J. (2010). Creating dynamic tensions through balanced use of management control systems. Accounting, Organizations and Society, 35(5), 499-523.

Normann, R. (1975). Skapande företagsledning. Stockholm: Bonnier Alba.

Perez-Freije, J., \& Enkel, E. (2007). Creative tension in the innovation process: How to support the right capabilities. European Management Journal, 25(1), 11-24.

Poole, M. S., \& Van de Ven, A. H. (1989). Using paradox to build management and organization theories. Academy of Management Review, 14(4), 562-578.

Poskela, J., \& Martinsuo, M. (2009). Management control and strategic renewal in the front end of innovation. Journal of Product Innovation Management, 26(6), 671-684.

Prajogo, D. I., \& McDermott, C. M. (2011). The relationship between multidimensional organizational culture and performance. International Journal of Operations and Production Management, 31(7), 712-735.

Pärl, Ü. (2014). The role of dialogue between executives and ground-level employees mediated by MACS. Baltic Journal of Management, 9(2), 189-212.

Raza-Ullah, T., Bengtsson, M., \& Kock, S. (2014). The coopetition paradox and tension in coopetition at multiple levels. Industrial Marketing Management, 43, 189-198.

Revellino, S., \& Mouritsen, J. (2009). The multiplicity of controls and the making of innovation. European Accounting Review, 18(2), 341-369.

Revellino, S., \& Mouritsen, J. (2015). Accounting as an engine: The performativity of calculative practices and the dynamics of innovation. Management Accounting Research, 28, 31-49.

Roberts, J. (1991). The possibilities of accountability. Accounting Organizations and Society, 16(4), 355368.

Silaen, P., \& Williams, R. (2009). Management control systems: A model for R\&D units. Accounting Research Journal, 22(3), 262-274.

Simons, R. (1995). Levers of control: How managers use innovative control systems to drive strategic renewal. Boston: Harvard Business School Press.

Smith, W. (2014). Dynamic decision making: A model of senior leaders managing strategic paradoxes. Academy of Management Journal, 57(6), 1592-1623.

Smith, W., \& Lewis, M. W. (2011). Toward a theory of paradox: A dynamic equilibrium model of organizing. Academy of Management Review, 36(2), 381-403.

Stewart, J. (2014). Implementing an innovative public sector program. International Journal of Public Sector Management, 27(3), 241-250.

Strauss, E., \& Zecher, C. (2013). Management control systems: A review. Journal of Management Control, 23(4), 233-268.

Teece, D. J., Pisano, G., \& Shuen, A. (1997). Dynamic capabilities and strategic management. Strategic Management Journal, 18(7), 509-533.

Tessier, S., \& Otley, D. (2012). A conceptual development of Simons' levers of control framework. Management Accounting Research, 23, 171-185.

Tranfield, D., Denyer, D., \& Smart, P. (2003). Towards a methodology of developing evidence-informed management knowledge by means of systematic review. British Journal of Management, 14, 207-222.

Verbeeten, F. H. M., \& Boons, A. N. A. M. (2009). Strategic priorities, performance measures and performance: An empirical analysis of Dutch firms. European Management Journal, 27, 113-128. 
Vlaar, P. W. L., van den Bosch, F. A. J., \& Volberda, H. W. (2007). Towards a dialectic perspective on formalization in interorganizational relationships: How alliance managers capitalize on the duality inherent in contracts, rules and procedures. Organization Studies, 28(4), 437-466.

Vosselman, E., \& van der Meer-Kooistra, J. (2009). Accounting for control and trust building in interfirm transactional relationships. Accounting, Organizations and Society, 34, 267-283.

Ylinen, M., \& Gullkvist, B. (2012). The effects of tolerance for ambiguity and task uncertainty on the balanced and combined use of project controls. European Accounting Review, 21(2), 395-415.

Ylinen, M., \& Gullkvist, B. (2014). The effects of organic and mechanistic control in exploratory and exploitative innovations. Management Accounting Research, 25, 93-112. 